\title{
Comparison of Methods for Estimating Unbound Intracellular-to-Medium Concentration Ratios in Rat and Human Hepatocytes Using Statins ${ }^{\text {[ }}$
}

\author{
Takashi Yoshikado, Kota Toshimoto, Tomohisa Nakada, Kazuaki Ikejiri, Hiroyuki Kusuhara, \\ Kazuya Maeda, and Yuichi Sugiyama
}

\begin{abstract}
Sugiyama Laboratory, RIKEN Innovation Center, RIKEN, Kanagawa, Japan (T.Y., K.T., Y.S.); DMPK Research Laboratories Sohyaku, Innovative Research Division, Mitsubishi Tanabe Pharma, Saitama, Japan (T.N.); and Laboratory of Molecular Pharmacokinetics, Graduate School of Pharmaceutical Sciences, University of Tokyo, Tokyo, Japan (K.I., H.K., K.M.)
\end{abstract}

\section{ABSTRACT}

It is essential to estimate concentrations of unbound drugs inside the hepatocytes to predict hepatic clearance, efficacy, and toxicity of the drugs. The present study was undertaken to compare predictability of the unbound hepatocyte-to-medium concentration ratios $\left(\mathrm{K}_{\mathrm{p}, \mathrm{uu}}\right)$ by two methods based on the steady-state cell-to-medium total concentration ratios at $37^{\circ} \mathrm{C}$ and on ice $\left(\mathrm{K}_{\mathrm{p}, \mathrm{uu}, \mathrm{ss}}\right)$ and based on their initial uptake rates

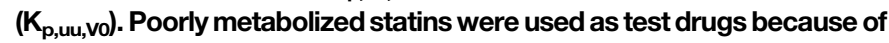
their concentrative uptake via organic anion-transporting polypeptides. $K_{p, u u, s s}$ values of these statins provided less interexperimental variation than the $K_{p, u u, v o}$ values, because only data at longer time are required for $K_{p, u u, s s} . K_{p, u u, v o}$ values for pitavastatin, rosuvastatin, and pravastatin were 1.2- to 5.1-fold $K_{p, u u, s s}$ in rat hepatocytes; $K_{p, u u, v o}$ values in human hepatocytes also tended to be larger than corresponding $K_{p, u u, s s:}$ To

explain these discrepancies, theoretical values of $K_{p, u u, s s}$ and $K_{p, u u, v o}$

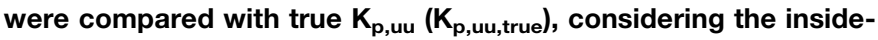
negative membrane potential and ionization of the drugs in hepatocytes and medium. Membrane potentials were approximately $-30 \mathrm{mV}$ in human hepatocytes at $37^{\circ} \mathrm{C}$ and almost abolished on ice. Theoretical equations considering the membrane potentials indicate that $K_{p \text {,uu,ss }}$ values for the statins are 0.85 - to 1.2 -fold $K_{p \text {,uu,true, }}$

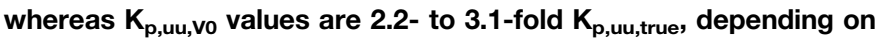
the ratio of the passive permeability of the ionized to nonionized forms. In conclusion, $K_{p, u u, s s}$ values of anions are similar to $K_{p, u u \text {,true }}$ when the inside-negative membrane potential is considered. This suggests that $K_{p, u u, s s}$ is preferable for estimating the concentration of unbound drugs inside the hepatocytes.

\section{Introduction}

According to the free drug hypothesis, only unbound drug is believed to interact with metabolic enzymes and pharmacological/toxicological target proteins. Knowing the intracellular unbound drug concentration is essential to estimate accurately the risk of drug-drug interactions involving drug-metabolizing enzymes and canalicular efflux transporters, and efficacy and toxicity of drugs when their targets are intracellular proteins. Extracellular unbound drug concentration is frequently assumed to be equivalent to the intracellular unbound concentration, especially when drugs are neutral or nonionized and freely permeable across the cytoplasmic membrane (Smith et al., 2010). However, this assumption cannot be applied to drugs whose tissue uptake is dominated by active

This work was supported by Grant-in-Aid for Scientific Research (S) and the Scientific Research on Innovative Areas HD-Physiology from the Ministry of Education, Culture, Sports, Sciences, and Technology in Japan [Grants 24229002 and 23136101].

T.Y., K.T., and T.N. contributed to this research equally.

https://doi.org/10.1124/dmd.116.074823.

S This article has supplemental material available at dmd.aspetjournals.org. transporters (Smith et al., 2005; Shugarts and Benet, 2009; Giacomini et al., 2010; Niemi et al., 2011; Shitara et al., 2013), in which their intracellular unbound concentration of drugs could be higher than the extracellular unbound concentration. For instance, unbound concentrations of pravastatin and rosuvastatin in the rat liver are 11- to 16-fold (Yamazaki et al., 1993; Nezasa et al., 2003) and 15-fold higher than unbound plasma concentrations, respectively, because of organic aniontransporting polypeptide (OATP)-mediated uptake (Nezasa et al., 2003).

Methods to estimate the unbound hepatocyte-to-medium concentration ratio $\left(\mathrm{K}_{\mathrm{p}, \mathrm{uu}}\right)$ are needed to predict the magnitude of drug-drug interactions involving drug-metabolizing enzymes, efflux transporters, and other intrahepatic target proteins in the liver. Brown et al. (2010) investigated the impact of transporters on the inhibition constant $\left(\mathrm{K}_{\mathrm{i}}\right)$ values of cytochrome P450 inhibitors by comparing their inhibitory effects using rat liver microsomes and freshly isolated rat hepatocytes. Using the hepatocytes, $\mathrm{K}_{\mathrm{i}}$ values of clarithromycin and enoxacin with known hepatic transporter involvement were markedly smaller than those using the microsomes, which was consistent with their high cellto-medium total concentration ratios ( $\mathrm{C} / \mathrm{M}$ ratios). The International Transporter Consortium published a review summarizing strategies to estimate intracellular drug concentrations (Chu et al., 2013). Among

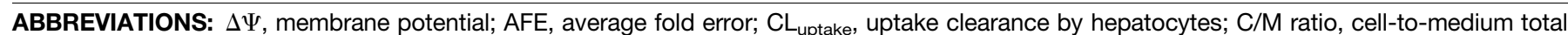
concentration ratio; $\mathrm{f}_{\mathrm{T}, \mathrm{cell}}, \mathrm{ss}$, unbound fraction in hepatocytes at steady state; $\mathrm{f}_{\mathrm{T}, \text { cell,vo, }}$, unbound fraction in hepatocytes based on initial uptake rate; $\mathrm{f}_{\mathrm{T}, \text { homogenate }}$, unbound fraction in liver homogenates; HBSS, Hanks' balanced salt solution; $\mathrm{K}_{\mathrm{i}}$, inhibition constant; $\mathrm{K}_{\mathrm{m}}$, Michaelis-Menten constant; $\mathrm{K}_{\mathrm{p}, \mathrm{uu}}$, unbound hepatocyte-to-medium concentration ratio; $\mathrm{K}_{\mathrm{p}, \mathrm{uu}, \mathrm{ss}}$, unbound hepatocyte-to-medium concentration ratio based on steady-state

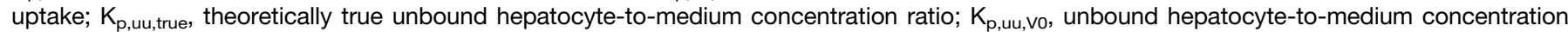
ratio based on initial uptake rate; MRP, multidrug resistance-associated protein; OATP, organic anion-transporting polypeptide; $P_{\text {dif }}$, influx intrinsic clearance by passive diffusion through sinusoidal membrane; $\mathrm{TPP}^{+}$, tetraphenylphosphonium; $\mathrm{V}_{\max }$, maximum transport rate. 
them, a strategy to estimate $\mathrm{K}_{\mathrm{p} \text {,uu }}$ based on the initial uptake rate $\left(\mathrm{K}_{\mathrm{p}, \mathrm{uu}, \mathrm{vo}}\right)$ calculated using active transport clearance $\left(\mathrm{V}_{\max } / \mathrm{K}_{\mathrm{m}}\right)$, and passive diffusion clearance at various concentrations (Yabe et al., 2011) was introduced. In addition, we have proposed an alternative strategy to estimate $\mathrm{K}_{\mathrm{p} \text {,uu }}$ under steady-state conditions $\left(\mathrm{K}_{\mathrm{p} \text {,uu,ss }}\right)$, which can be calculated by dividing the $\mathrm{C} / \mathrm{M}$ ratio at $37^{\circ} \mathrm{C}$ by that at a low temperature (on ice) or in the presence of ATP depletors, when active transport is stopped (Yamazaki et al., 1992; Shitara et al., 2013). Yamazaki et al. (1993) demonstrated that the uptake of pravastatin by rat hepatocytes was more greatly reduced at a low temperature than by ATP depletion.

In the present study, steady-state uptake of typical OATP substrates, pitavastatin, rosuvastatin, and pravastatin in rat and human hepatocytes

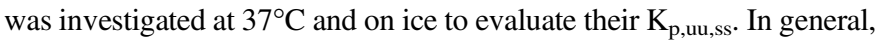
$\mathrm{K}_{\mathrm{p} \text {,uu }}$ can be described by the $\mathrm{C} / \mathrm{M}$ ratio of drugs in hepatocytes as follows:

$$
C / M \text { ratio }=\frac{C_{\text {cell }}}{C_{\text {medium }}}=\frac{C_{\text {cell,unbound }} / f_{T}}{C_{\text {medium,unbound }} / f_{B}}=K_{p, u u} \cdot \frac{f_{B}}{f_{T}},
$$

where $f_{B}$ is the unbound fraction of the drugs in the blood (in vivo) or in the incubation medium (in vitro), and $\mathrm{f}_{\mathrm{T}}$ is the unbound fraction of the drugs in the hepatocytes. The unbound fraction in hepatocytes at the steady state $\left(\mathrm{f}_{\mathrm{T}, \text { cell,ss }}\right)$ obtained using our method should be validated because intracellular binding to cytosolic proteins/cellular organelles might be altered at low temperatures. Therefore, $\mathrm{f}_{\mathrm{T}, \mathrm{cell}, \mathrm{ss}}$ were compared with the unbound fraction in liver homogenates $\left(f_{T, \text { homogenate }}\right)$ measured by equilibrium dialysis using human liver samples. The $\mathrm{K}_{\mathrm{p} \text {,uu,ss }}$ obtained were then compared with $\mathrm{K}_{\mathrm{p} \text {,uu,Vo }}$ in both rat and human hepatocytes. The difference between $\mathrm{K}_{\mathrm{p} \text {,uu,ss }}$ or $\mathrm{K}_{\mathrm{p} \text {,uu,vo }}$ and true $\mathrm{K}_{\mathrm{p} \text {,uu }}\left(\mathrm{K}_{\mathrm{p} \text {,uu,true }}\right)$ is discussed in the context of theoretical equations, considering the membrane potential $(\Delta \Psi)$ in hepatocytes and the fraction of ionized drugs at the designated $\mathrm{pH}$. Finally, a method to predict $\mathrm{K}_{\mathrm{p} \text {,uu,true }}$ from $\mathrm{K}_{\mathrm{p} \text {,uu,ss }}$ and $\mathrm{K}_{\mathrm{p} \text {,uu,vo }}$ obtained experimentally is proposed.

\section{Materials and Methods}

Chemicals. $\left[{ }^{3} \mathrm{H}\right]$ Pitavastatin, $\left[{ }^{3} \mathrm{H}\right]$ rosuvastatin calcium, and $\left[{ }^{3} \mathrm{H}\right]$ pravastatin calcium were obtained from American Radiolabeled Chemicals (St. Louis, MO). $\left[{ }^{3} \mathrm{H}\right]$ Diazepam was obtained from PerkinElmer Life Sciences (Boston, MA). Unlabeled diazepam, pitavastatin calcium, rosuvastatin calcium, and pravastatin sodium were obtained from Wako Pure Chemicals (Osaka, Japan). All other reagents and solvents were purchased from Invitrogen (Carlsbad, CA), SigmaAldrich (St. Louis, MO), and Wako Pure Chemicals.

Animals. Male Sprague-Dawley rats were purchased from Charles River Japan (Shiga, Japan) and acclimatized for $>7$ days before the experiments. The rats were housed under conditions of controlled temperature and humidity with a 12-hour light/dark cycle with free access to standard laboratory rodent food (CE-2; CLEA Japan, Tokyo, Japan) and water. All animal experiments were approved by the Experimental Animal Care and Use Committee of the Mitsubishi Tanabe Pharma (Saitama, Japan) and conducted in accordance with the Declaration of Helsinki and the guidelines of the ethics committee.

Isolation of Rat Hepatocytes. Hepatocytes were isolated from male SpragueDawley rats (7-9 weeks old) using a procedure described previously (Baur et al., 1975). Isolated hepatocytes were suspended in albumin-free Krebs-Henseleit buffer with $12.5 \mathrm{mM}$ HEPES (pH 7.4), and cell viabilities were determined using a trypan blue exclusion test. Hepatocytes obtained from three independent preparations with $>80 \%$ viability were used for the uptake studies described below.

Preparation of Human Hepatocytes. Human biologic samples were obtained ethically, and their research use was in accordance with the terms of informed consent. Cryopreserved human hepatocytes from a donor (Lot Hu8075) were purchased from Life Technologies (Carlsbad, CA). Pooled cryopreserved human hepatocytes from 20 mixed-sex donors (Lot TFF) were purchased from BioreclamationIVT (Baltimore, MD). Pooled cryopreserved human hepatocytes from 50 mixed-sex donors (Lot HUE50C) were purchased from Thermo Fisher Scientific (Waltham, MA). These hepatocytes were suspended in albumin-free Krebs-Henseleit buffer with $12.5 \mathrm{mM}$ HEPES (pH 7.4), and viabilities were determined using a trypan blue exclusion test. Hepatocytes obtained from three independent preparations with $>80 \%$ viability were used for the uptake studies described below.

Determination of the Intracellular Volume of Hepatocytes. The intracellular volume of rat hepatocytes $\left(3.68 \pm 1.37 \mu \mathrm{L} / 10^{6}\right.$ cells $)$ was estimated using published methods (Supplemental Table 1A) (Baur et al., 1975; Kletzien et al., 1975; Eaton and Klaassen, 1978; Kristensen and Folke, 1984; Yamazaki et al., 1992; Miyauchi et al., 1993; Reinoso et al., 2001; Hallifax and Houston, 2006). In brief, to determine the intracellular volume of human hepatocytes, cryopreserved human hepatocytes (Lot Hu8075) were suspended in Krebs-Henseleit buffer (pH 7.4) at $6.0 \times 10^{6}$ viable cells $/ \mathrm{mL}$ and preincubated at $37^{\circ} \mathrm{C}$ for 5 minutes. A reaction was initiated by adding an equal volume of buffer containing $\left[{ }^{3} \mathrm{H}\right]$ water and $\left[{ }^{14} \mathrm{C}\right]$ dextran at final concentrations of $2.5 \mu \mathrm{Ci} / \mathrm{mL}$ and $0.5 \mu \mathrm{Ci} / \mathrm{mL}$, respectively. After incubation at $37^{\circ} \mathrm{C}$ for 10 minutes, during which the distribution of $\left[{ }^{3} \mathrm{H}\right]$ water and $\left[{ }^{14} \mathrm{C}\right]$ dextran reached a steady state, aliquots were removed and added to a narrow tube containing silicone-mineral oil (density: 1.015; SigmaAldrich) over aqueous $2 \mathrm{M}$ sodium hydroxide, followed by centrifugation through the silicone-mineral oil layer to separate the cells from the medium. After the basic bottom layer was neutralized with $2 \mathrm{M}$ hydrochloric acid, radioactivities in both cells and medium were determined using a Tri-Carb liquid scintillation counter (PerkinElmer, Shelton, CT). Thereby, the intracellular volume of human hepatocytes was estimated to be $2.28 \pm 0.33 \mu \mathrm{L} / 10^{6}$ cells (Supplemental Table 1B)

Determination of $K_{p, u u, s s}$ and $f_{T, c e l l, s s}$ in Rat and Human Hepatocytes Based on Steady-State Uptake. To determine the incubation time for steadystate uptake into hepatocytes, transport studies were performed by an oil-spin method (Iga et al., 1979) using suspended hepatocytes. Hepatocytes were suspended in Krebs-Henseleit buffer $(\mathrm{pH} 7.4)$ at $2.0 \times 10^{6}$ viable cells $/ \mathrm{mL}$ and preincubated at $37^{\circ} \mathrm{C}$ for 5 minutes. A reaction was initiated by adding an equal volume of buffer containing each drug (pitavastatin, rosuvastatin, pravastatin, or diazepam previously used as a neutral drug with high membrane permeability for evaluating the uptake into isolated rat hepatocytes) (Ichikawa et al., 1992) at $1 \mu \mathrm{M}$. After incubation at $37^{\circ} \mathrm{C}$ for $0.5,2,5,15$, and 30 minutes (rat hepatocytes), $0.5,5,15,30$, and 60 minutes (human hepatocytes, Lot Hu8075), or 0.5, 1.5, 30, and 60 minutes (human hepatocytes, Lot TFF), aliquots were removed and added to a narrow tube containing silicone-mineral oil over aqueous $2 \mathrm{M}$ sodium hydroxide and centrifuged through the silicone-mineral oil layer to separate the cells from the medium. To provide low temperature values, the uptake studies were performed on ice. After the basic bottom layer was neutralized with $2 \mathrm{M}$ hydrochloric acid, radioactivity in both cells and medium was measured using the liquid scintillation counter.

The unbound hepatocyte-to-medium concentration ratio $\left(\mathrm{K}_{\mathrm{p}, \mathrm{uu}}\right)$ based on the steady-state uptake ratio at $37^{\circ} \mathrm{C}$ and on ice $\left(\mathrm{K}_{\mathrm{p}, \mathrm{uu}, \mathrm{ss}}\right)$ and the unbound fraction in hepatocytes based on the steady-state uptake $\left(\mathrm{f}_{\mathrm{T}, \mathrm{cell}, \mathrm{ss}}\right)$ were defined as described in eqs. 2 and 3, respectively, based on the $\mathrm{C} / \mathrm{M}$ ratio at $37^{\circ} \mathrm{C}$ and on ice. A part of the method to obtain $\mathrm{f}_{\mathrm{T}, \text { cell,ss }}$ was reported previously (Yoshikado et al., 2016).

$$
\begin{aligned}
& K_{p, \text { uu }, \text { ss }}=\frac{C / \text { Mratio }_{37^{\circ} \mathrm{C}}}{C / \text { Mratio on ice }_{\text {oc }}}=\frac{C_{\text {cell }, 37^{\circ} \mathrm{C}} / C_{\text {medium }, 37^{\circ} \mathrm{C}}}{C_{\text {cell,on ice }} / C_{\text {medium,on ice }}} \\
& =\frac{C_{\text {cell,unbound }, 37^{\circ} \mathrm{C}} / C_{\text {medium }, 37^{\circ} \mathrm{C}} / f_{T, \text { cell }, 37^{\circ} \mathrm{C}}}{C_{\text {cell, unbound,on ice }} / C_{\text {medium,on ice }} / f_{T, \text { cell,on ice }}} \\
& =\frac{C_{\text {cell, } \text {,unbound }, 37^{\circ} \mathrm{C}}}{C_{\text {medium }, 37^{\circ} \mathrm{C}}} \\
& f_{T, \text { cell,ss }}=\frac{C_{\text {cell,unbound,on ice }}}{C_{\text {medium, on ice }}} \cdot \frac{C_{\text {medium }, \text { on ice }}}{C_{\text {cell,on ice }}}=\frac{1}{C / \text { M ratio on ice }}
\end{aligned}
$$

The following assumptions were made in calculating $\mathrm{K}_{\mathrm{p}, \mathrm{uu}, \mathrm{ss}}$ and $\mathrm{f}_{\mathrm{T}, \mathrm{cell} \text {,ss }}$ using eqs. 2 and 3: the active uptake in hepatocytes is abolished on ice (i.e., $\mathrm{C}_{\text {cell,unbound,on ice }}$ is equal to $\mathrm{C}_{\text {medium,on ice), and }} \mathrm{f}_{\mathrm{T}, \text { cell,ss }}$ is independent of temperature (i.e., $\mathrm{f}_{\mathrm{T}, \text { cell,ss,on ice }}$

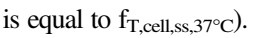

Determination of $K_{p, u u, v 0}, f_{T, c e l l, v 0}$, and Other Kinetic Parameters in Rat and Human Hepatocytes Based on Initial Uptake Rate. To evaluate the initial uptake rate in pooled human hepatocytes, hepatocytes were preincubated for 5 minutes and then incubated for $0.5-1.5$ or $0.5-2$ minutes, as shown in the transport studies described above. 
TABLE 1

Determination of $\lambda$ based on the $\mathrm{pH}$-dependent permeation data of statins observed in Caco-2 cells

Values are shown as the mean \pm S.D.

\begin{tabular}{|c|c|c|c|c|c|c|c|}
\hline Drug & $\mathrm{f}_{\mathrm{i}, \text { ion }}{ }^{a}$ & $\mathrm{f}_{\mathrm{i}, \text { uion }}{ }^{a}$ & $\mathrm{f}_{\mathrm{o}, \text { ion }}{ }^{a}$ & $\mathrm{f}_{\mathrm{o} \text {,uion }}{ }^{a}$ & $\mathrm{pKa}^{b}$ & $\mathrm{PS}_{\text {dif,inf,uion,Caco-2 }}^{c} \times 10^{-6}$ & $\lambda^{c}$ \\
\hline & & & & & & $\mu L / \mathrm{min} /$ well & \\
\hline Pitavastatin & 0.857 & 0.143 & 0.905 & 0.095 & 4.46 & $3487 \pm 1403$ & $0.0282 \pm 0.0204$ \\
\hline Rosuvastatin & 0.986 & 0.014 & 0.991 & 0.009 & 4.6 & $714 \pm 68$ & $0.0112 \pm 0.0035$ \\
\hline Pravastatin & 0.986 & 0.014 & 0.991 & 0.009 & 4.6 & $111 \pm 19$ & $0.188 \pm 0.038$ \\
\hline
\end{tabular}

${ }^{a}$ The $\mathrm{f}_{\mathrm{i}, \text { ion }}$ and $\mathrm{f}_{\mathrm{o} \text {,ion }}$ were calculated based on Henderson-Hasselbalch equation assuming that intracellular $\mathrm{pH}$ and medium $\mathrm{pH}$ are 7.2 and 7.4 , respectively. The $f_{i, \text { uion }}$ and $f_{o \text {,uion }}$ were subtracted $f_{i, \text { ion }}$ and $f_{o, \text { ion }}$ from one, respectively.

${ }^{b}$ Fixed at values obtained from the manufacturer's Interview Forms.

${ }^{c} \mathrm{The}_{\mathrm{PS}} \mathrm{dif}_{\text {,inf,uion,Caco-2 }}$ and $\lambda$ were determined by fitting eq. 9 to the $\mathrm{pH}$-dependent permeation data of statins observed in Caco-2 cells (Supplemental Fig. 1).

The uptake clearance by hepatocytes $\left(\mathrm{CL}_{\text {uptake }}\right)$ was determined by the slope of the plot of $\mathrm{C} / \mathrm{M}$ ratio versus time, and the initial uptake rate $(v)$ was calculated by multiplying $\mathrm{CL}_{\text {uptake }}$ with the initial substrate concentration.

According to a method reported previously (Yabe et al., 2011), $v$ can be calculated using eq. 4 :

$$
v=\frac{V_{\max } \cdot S}{K_{m}+S}+P S_{d i f} \cdot S
$$

where $\mathrm{V}_{\max }$ is the maximum uptake rate, $\mathrm{K}_{\mathrm{m}}$ is the Michaelis constant, $\mathrm{PS}_{\text {dif }}$ is the passive diffusion clearance, and $\mathrm{S}$ is the substrate concentration in the medium. These kinetic parameters were optimized by fitting the equation to observed data using Phoenix WinNonlin version 6.3 (Pharsight Certara, St. Louis, $\mathrm{MO}$ ). Because $\mathrm{CL}_{\text {uptake }}$ consists of active uptake clearance $\left(\mathrm{PS}_{\mathrm{act}}\right)$ and passive diffusion clearance $\left(\mathrm{PS}_{\mathrm{dif}}\right)$, assuming that $\mathrm{PS}_{\text {dif }}$ for the cellular uptake is equal to that for the efflux, $\mathrm{K}_{\mathrm{p} \text {,uu }}$ and $\mathrm{f}_{\mathrm{T} \text {, cell }}$ based on initial uptake rate $\left(\mathrm{K}_{\mathrm{p}, \mathrm{uu}, \mathrm{V} 0}, \mathrm{f}_{\mathrm{T}, \text { cell,vo }}\right)$ can be calculated using eqs. 5 and 6 (Yabe et al., 2011):

$$
\begin{aligned}
\mathrm{K}_{\mathrm{p}, \mathrm{uu}, \mathrm{V} 0} & =\frac{\mathrm{PS}_{\mathrm{act}}+\mathrm{PS}_{\mathrm{dif}}}{\mathrm{PS}_{\mathrm{dif}}}, \\
\mathrm{f}_{\mathrm{T}, \mathrm{cell}, \mathrm{V} 0} & =\frac{\mathrm{K}_{\mathrm{p}, \mathrm{uu}, \mathrm{V} 0}}{\mathrm{C} / \mathrm{M} \text { ratio }_{37^{\circ} \mathrm{C}}},
\end{aligned}
$$

where the $\mathrm{C} / \mathrm{M}$ ratio $_{37^{\circ} \mathrm{C}}$ in rat hepatocytes was obtained at 30 minutes, and that in human hepatocytes was obtained at 60 minutes.

Determination of the Unbound Fraction in Human Liver Homogenates ( $\mathbf{f}_{\text {T,homogenate }}$ ) Using Equilibrium Dialysis. Human liver samples were obtained from the Human and Animal Bridging Research Organization (Tokyo, Japan) with approval of the Ethics Committees of University of Tokyo and Human and Animal Bridging Research Organization. Three lots of liver samples were pooled and homogenized in $66.7 \mathrm{mM}$ isotonic phosphate buffer at 1:3 (w/v) producing $25 \%$ homogenates. By diluting these homogenates, $12.5 \%$ and $6.25 \%$ homogenates were also prepared. Diazepam, pitavastatin, pravastatin, and rosuvastatin (final concentrations: $0.2 \mu \mathrm{M}$ ) were added to the compartment containing homogenates in a Rapid Equilibrium Dialysis plate (Thermo Fisher Scientific) and incubated for 12 hours at $37^{\circ} \mathrm{C}$, or on ice.
A

Diazepam (rat)

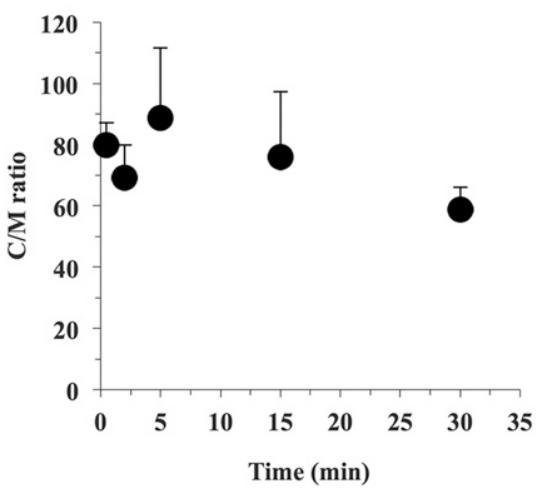

C

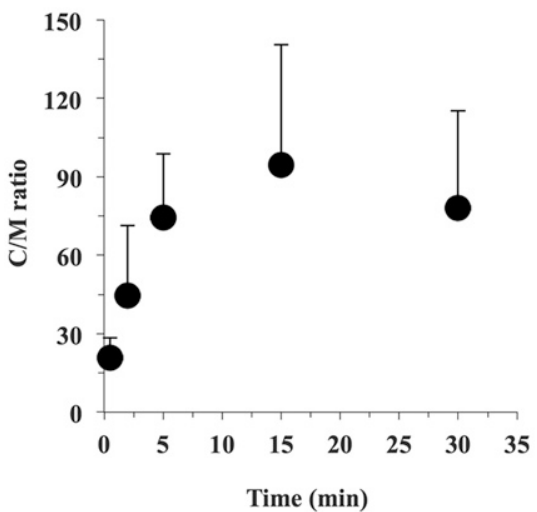

B

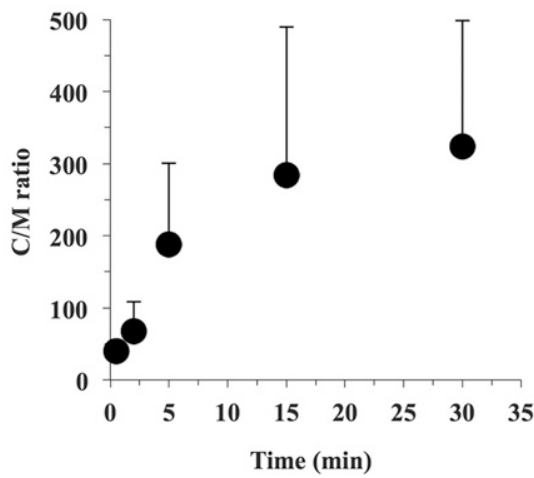

D

Pravastatin (rat)

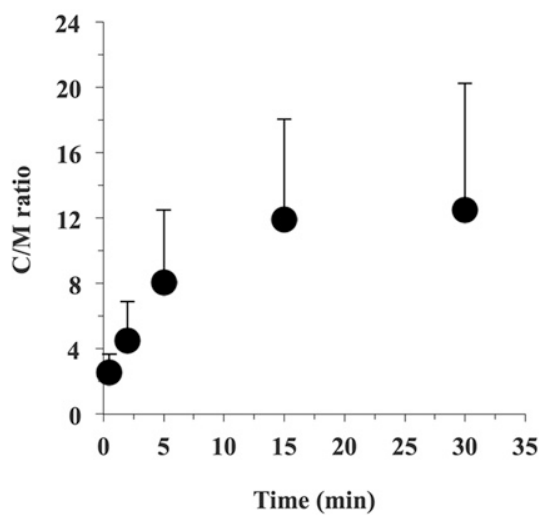

Fig. 1. Uptake of diazepam (1 $\mu \mathrm{M} ; \mathrm{A})$, pitavastatin $(1 \mu \mathrm{M}$; B), rosuvastatin $(1 \mu \mathrm{M} ; \mathrm{C})$, and pravastatin $(1 \mu \mathrm{M} ; \mathrm{D})$ by rat hepatocytes measured after incubation at $37^{\circ} \mathrm{C}$ for $0.5-30$ minutes. The data are presented as mean + S.D. $(n=3)$. 
TABLE 2

$\mathrm{K}_{\mathrm{p}, \mathrm{uu}, \mathrm{ss}}$ and $\mathrm{f}_{\mathrm{T}, \mathrm{cell}, \mathrm{ss}}$ in rat hepatocytes

Values are shown as the mean \pm S.D. $(n=3)$.

\begin{tabular}{|c|c|c|c|c|}
\hline \multirow[t]{2}{*}{ Drug } & \multicolumn{2}{|c|}{ C/M Ratio ${ }^{a}$} & \multirow[t]{2}{*}{$\mathrm{K}_{\mathrm{p}, \mathrm{uu}, \mathrm{ss}}{ }^{b}$} & \multirow[t]{2}{*}{$\mathrm{f}_{\mathrm{T}, \text { cell, ss }}{ }^{b}$} \\
\hline & $37^{\circ} \mathrm{C}$ & On ice & & \\
\hline Diazepam & $58.9 \pm 7.3$ & $69.3 \pm 9.7$ & $0.851 \pm 0.024$ & $0.0147 \pm 0.0022$ \\
\hline Pitavastatin & $324 \pm 174$ & $29.6 \pm 11.5$ & $10.8 \pm 4.4$ & $0.0381 \pm 0.0167$ \\
\hline Rosuvastatin & $78.1 \pm 37.1$ & $7.80 \pm 4.07$ & $13.1 \pm 7.7$ & $0.149 \pm 0.060$ \\
\hline Pravastatin & $12.5 \pm 7.7$ & $1.80 \pm 0.56$ & $6.69 \pm 2.76$ & $0.600 \pm 0.217$ \\
\hline
\end{tabular}

${ }^{a} \mathrm{C} / \mathrm{M}$ ratios were calculated using the uptake data at 30 minutes (Fig. 1).

${ }^{b}$ The $\mathrm{K}_{\mathrm{p}, \mathrm{uu}, \mathrm{ss}}$ and $\mathrm{f}_{\mathrm{T}, \text { cell,ss }}$ were calculated from C/M ratios using eqs. 2 and 3, respectively.

Calculation of the Ratio of Passive Diffusion Influx Clearance of Ionized Drug to That of Nonionized Drug $(\lambda)$ Based on the pH-Dependent Permeability Examined in Caco-2 Cells. Caco-2 cells were obtained from American Type Culture Collection (Rockville, MD). Cells (passages 28-40) were cultivated, as previously described (Neuhoff et al., 2003), with some modifications. Briefly, Caco-2 cells were seeded onto a Millicell-96 Cell Culture Insert Plate (polycarbonate $0.4 \mu \mathrm{m}$; Merck Millipore, Billerica, MA) at $2.5 \times 10^{5}$ cells/well, and the culture medium was changed every second day. On day 10, transport experiments were performed; the incubation medium was Hanks' balanced salt solution (HBSS) buffered with either $20 \mathrm{mM}$ 4-morpholineethanesulfonic acid $(\mathrm{pH}=5.5,6.0$, and 6.5), or $20 \mathrm{mM}$ HBSS ( $\mathrm{pH}=7.4)$. Before the experiments, the apical side of the Caco- 2 cell monolayer was washed four times with HBSS at the corresponding $\mathrm{pHs}$ (5.5, 6.0, 6.5 , and 7.4). Then, both apical and basal sides of the monolayer were preincubated for 10 minutes at $37^{\circ} \mathrm{C}$ in the presence of rifamycin SV $(100 \mu \mathrm{M})$, cyclosporin A $(10 \mu \mathrm{M})$, and Ko143 $(10 \mu \mathrm{M})$ as OATP2B1, P-glycoprotein, and breast cancer resistance protein inhibitors, respectively, at corresponding $\mathrm{pHs}$ (5.5, 6.0, 6.5, and 7.4 for the apical side, and 7.4 for the basal side). Subsequently, the monolayer was incubated for $10,30,60$, and 90 minutes at $37^{\circ} \mathrm{C}$ in the presence of each radiolabeled statin $(10 \mu \mathrm{M}$, apical side only) and the inhibitors (both sides). Lucifer yellow $(300 \mu \mathrm{M})$ was used as a paracellular marker to examine the integrity of the monolayer. The radioactivity on the basal side was determined using a liquid scintillation counter.

The $\mathrm{PS}_{\mathrm{dif}, \text { inf }}$ is expressed as follows:

$$
P S_{\text {dif }, \text { inf }}=f_{o, \text { ion }} \cdot P S_{\text {dif }, \text { inf,ion }}+f_{o, \text { uion }} \cdot P S_{\text {dif }, \text { inf }, \text { uion }}
$$

where the subscripts ion and uion represent the ionized and unionized (nonionized) form of a drug, respectively, and $\mathrm{f}_{\mathrm{o} \text {,ion }}$ and $\mathrm{f}_{\mathrm{o} \text {,uion }}$ are fractions of ionized and nonionized drug outside the cells, respectively. Subsequently, $\lambda$ was defined as the ratio of passive diffusion influx clearance of the ionized drug to that of the nonionized drug, as follows:

$$
\lambda=\frac{P S_{d i f, \text { inf }, \text { ion }}}{P S_{d i f, \text { inf }, \text { uion }}} .
$$

It is assumed that the $\lambda$ value is not changed by temperature: the effect of low temperature on $\mathrm{PS}_{\mathrm{dif}, \text { inf,ion }}$ is assumed to be the same as that on $\mathrm{PS}_{\mathrm{dif}, \text { inf,uion, }}$ although these passive diffusion clearances should be affected by the change in membrane fluidity at low temperature (Kanduser et al., 2008). A part of the method to obtain $\lambda$ was reported previously (Yoshikado et al., 2016). Using $\lambda$, eq. 7 can be converted as follows:

$$
\begin{aligned}
P S_{d i f, \text { inf }} & =\left(1-f_{o, \text { uion }}\right) \cdot P S_{d i f, \text { inf }, \text { ion }}+f_{o, \text { uion }} \cdot P S_{\text {dif }, \text { inf }, \text { uion }} \\
& =\left(\lambda \cdot\left(1-f_{o, \text { uion }}\right)+f_{o, \text { uion }}\right) \cdot P S_{\text {dif }, \text { inf }, \text { uion }} \\
& =\left(\lambda+(1-\lambda) \cdot f_{o, \text { uion }}\right) \cdot P S_{d i f, \text { inf }, \text { uion }} \\
& =\left(\lambda+\frac{(1-\lambda)}{10^{p H-p K a}+1}\right) \cdot P S_{d i f, \text { inf }, \text { uion } .}
\end{aligned}
$$

The $\mathrm{f}_{\mathrm{o} \text {,ion }}$ and $\mathrm{f}_{\mathrm{o} \text {,uion }}$ for each statin were estimated using the $\mathrm{pH}$ of the medium (7.4) and pKa of the drug obtained from the manufacturer's Interview Forms, based on the Henderson-Hasselbalch equation (Table 1). Then, $\lambda$ and $\mathrm{PS}_{\mathrm{dif}, \text { inf,uion }}$ in Caco- 2 cells were optimized by fitting eq. 9 to the $\mathrm{pH}$-dependent membrane permeation of statins (Supplemental Fig. 1). Phoenix WinNonlin software version 6.3 (Pharsight Certara) was used to optimize the parameters. The obtained $\lambda$ values for pitavastatin, rosuvastatin, and pravastatin are shown in Table 1.

Measurement of the Membrane Potential Using a Lipophilic Cation. Tetraphenylphosphonium $\left(\mathrm{TPP}^{+}\right)$is a lipophilic cation that has been used as a probe to determine the $\Delta \Psi$. Saito et al. (1992) suggested a method to evaluate the $\Delta \Psi$ with $\mathrm{TPP}^{+}$correcting for its binding to intracellular constituents and its significant accumulation in mitochondria. By measuring the $\mathrm{C} / \mathrm{M}$ ratio of $\mathrm{TPP}^{+}, \Delta \Psi$ is calculated as described in eq. 10 (Saito et al., 1992):

$$
\Delta \Psi=-(R T / F) \ln \left(\frac{C / M_{\text {phys }} \text { ratio }}{C / M_{\text {abol }} \text { ratio }}\right),
$$

where $\mathrm{R}, \mathrm{T}$, and $\mathrm{F}$ are the gas constant, absolute temperature, and Faraday constant, respectively. $C / M_{\text {phys }}$ and $C / M_{a b o l}$ are the $C / M$ under physiologic conditions and when the $\Delta \Psi$ is abolished, respectively. The selective abolition of $\Delta \Psi$ can be achieved by rendering the cytoplasmic membrane permeable with $20 \mu \mathrm{M}$ amphotericin B (Saito et al., 1992). To measure the C/M ratio of $\mathrm{TPP}^{+}$, transport studies were performed using an oil-spin method (Iga et al., 1979) with cryopreserved human hepatocytes (Lot HUE50C). Hepatocytes were suspended in Krebs-Henseleit buffer $(\mathrm{pH} 7.4)$ at $2.0 \times 10^{6}$ viable cells $/ \mathrm{mL}$ and preincubated at $37^{\circ} \mathrm{C}$ for 5 minutes. The reaction was initiated by adding an equal volume of buffer containing $\mathrm{TPP}^{+}$(final: $3 \mu \mathrm{M}$ ) and amphotericin B (final: $20 \mu \mathrm{M}$ ). After incubation at $37^{\circ} \mathrm{C}$ for $0.5,15,30$, and 60 minutes, aliquots were removed and added to a narrow tube containing silicone-mineral oil over a $2.5 \mathrm{M}$ ammonium acetate, and then centrifuged to separate the cells from the medium. To examine the effect of low temperature on $\Delta \Psi$, uptake studies were also performed on ice. The concentrations of $\mathrm{TPP}^{+}$in the cells and the medium were determined using a liquid chromatography-tandem mass spectrometry (LC-MS/MS) system equipped with a Nexera UHPLC and a LCMS-8050 triplequadrupole liquid chromatograph mass spectrometer (Shimadzu, Kyoto, Japan). A Kinetex C18 column $(2.6 \mu \mathrm{m}, 3 \mathrm{~mm} \times 100 \mathrm{~mm}$; Phenomenex, Torrance, CA) was used, and UHPLC was conducted under gradient mobile-phase conditions with a mixture of $0.1 \%$ formic acid in water and $0.1 \%$ formic acid in acetonitrile as solvents $(0.3 \mathrm{~mL} / \mathrm{min} ; 0-0.5$ minute $95: 5 \mathrm{v} / \mathrm{v}, 0.5-3.5$ minutes $95: 5$ to $15: 85 \mathrm{v} / \mathrm{v}, 3.5-5$ minutes $15: 85 \mathrm{v} / \mathrm{v}, 5-5.5$ minutes $15: 85$ to $5: 95 \mathrm{v} / \mathrm{v}, 5.5-6$ minutes $5: 95 \mathrm{v} / \mathrm{v}, 6-6.1$ minutes 5 : 95 to $95: 5 \mathrm{v} / \mathrm{v}$, and $6.1-6.5$ minutes $95: 5 \mathrm{v} / \mathrm{v}$ ). The UHPLC eluent was introduced into the MS in positive electrospray ionization (ESI) mode. $\mathrm{TPP}^{+}$was quantified in multiple reaction monitoring mode $(339.10>183.10$; Q1 prebias: $-30.0 \mathrm{~V}, \mathrm{CE}:-54.0$, Q3 prebias: $-17.0 \mathrm{~V})$, in which chlorpropamide was used as an internal standard (277.20 > 111.05; Q1 prebias: $-18.0 \mathrm{~V}, \mathrm{CE}:-32.0$, Q3 prebias: $-20.0 \mathrm{~V})$.

Evaluation of the Correlation between $K_{p, u u}$ Values Examined by the Two Different Methods. To quantitatively evaluate the correlation between $\mathrm{K}_{\mathrm{p} \text {,uu,ss }}$ and $\mathrm{K}_{\mathrm{p}, \mathrm{uu}, \mathrm{V} 0}$, commonly employed accuracy test criteria, the average fold errors (AFE), were calculated, as shown in eq. 11.

TABLE 3

Kinetic parameters for the initial uptake rates of pitavastatin, rosuvastatin, and pravastatin in rat hepatocytes

Values are shown as the mean \pm S.D.

\begin{tabular}{lcccccr}
\hline \multicolumn{1}{c}{ Drug } & $\mathrm{V}_{\max }{ }^{a}$ & $\mathrm{~K}_{\mathrm{m}}{ }^{a}$ & $\mathrm{~V}_{\max } / \mathrm{K}_{\mathrm{m}}$ & $\mathrm{PS}_{\text {dif }}{ }^{a}$ & $\mathrm{~K}_{\mathrm{p}, \text { uu, v }{ }^{b}}$ & $\mathrm{f}_{\mathrm{T}, \text { cell, } \mathrm{vo}{ }^{b}}$ \\
\hline & $\mathrm{pmol} / \mathrm{min} / 10^{6}$ Cells & $\mu \mathrm{M}$ & $\mu \mathrm{L} / \mathrm{min} / 10^{6} \mathrm{Cells}$ & $\mu \mathrm{L} / \mathrm{min} / 10^{6} \mathrm{Cells}$ & & \\
Pitavastatin & $893 \pm 124$ & $5.43 \pm 1.29$ & $164 \pm 45$ & $3.00 \pm 1.41$ & $55.8 \pm 29.9$ & $0.172 \pm 0.131$ \\
Rosuvastatin & $250 \pm 80$ & $2.86 \pm 1.82$ & $87.4 \pm 62.3$ & $1.76 \pm 1.15$ & $50.7 \pm 48.0$ & $0.649 \pm 0.688$ \\
Pravastatin & $178 \pm 11$ & $20.3 \pm 1.4$ & $8.77 \pm 0.81$ & $1.16 \pm 0.08$ & $8.56 \pm 0.87$ & $0.685 \pm 0.428$ \\
\hline
\end{tabular}

${ }^{a}$ The initial uptake rate in rat hepatocytes was calculated from the uptake of $\left[{ }^{3} \mathrm{H}\right]$ pitavastatin, $\left[{ }^{3} \mathrm{H}\right]$ rosuvastatin, and $\left[{ }^{3} \mathrm{H}\right]$ pravastatin for $0.5-1.5$ minutes. Kinetic parameters are obtained by fitting to the data at seven concentrations $(0.1,0.3,1,3,10,30$, and $100 \mu \mathrm{M}$ for all statins; Supplemental Fig. 2) using eq. 4 .

${ }^{b}$ The $\mathrm{K}_{\mathrm{p}, \mathrm{uu}, \mathrm{Vo}}$ and $\mathrm{f}_{\mathrm{T}, \text { cell,vo }}$ were calculated using eqs. 5 and 6 , respectively. C/M ratios at $37^{\circ} \mathrm{C}$ (Table 2 ) were used for the calculation of the $\mathrm{f}_{\mathrm{T}, \text { cell,vo. }}$ 


$$
A F E=10^{\frac{\sum_{i=1}^{n}\left|\log \frac{K_{p, u, u, V 0}}{K_{p, u t u s s}}\right|}{n}}
$$

\section{Results}

Determination of $\mathbf{K}_{\mathbf{p} \text {,uu,ss }}$ and $\mathbf{f}_{\mathrm{T}, \mathrm{cell}, \mathrm{ss}}$ in Rat Hepatocytes. The time-dependent uptake of diazepam (a lipophilic neutral compound) and pitavastatin, rosuvastatin, and pravastatin (substrates of hepatic OATPs) in rat hepatocytes was monitored. The uptake of diazepam in rat hepatocytes reached a steady state instantaneously because of its high permeability, whereas the uptake of pitavastatin, rosuvastatin, and pravastatin gradually increased over time and reached the steady state within 30 minutes (Fig. 1). On ice, C/M ratios of pitavastatin, rosuvastatin, and pravastatin were significantly smaller than the ratios at $37^{\circ} \mathrm{C}$, whereas that for diazepam was not different from that at $37^{\circ} \mathrm{C}$ (Table 2). The $\mathrm{K}_{\mathrm{p} \text {,uu,ss }}$ for diazepam was 0.85 , and the values for

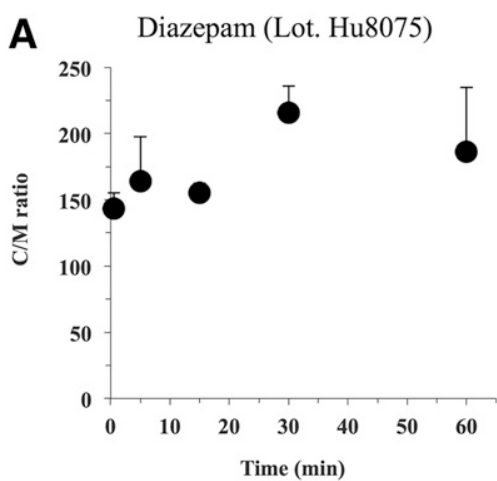

C

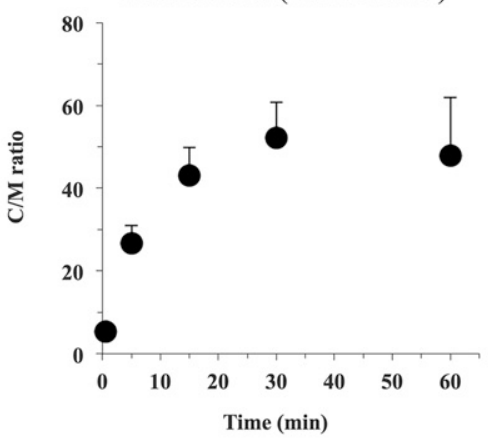

E

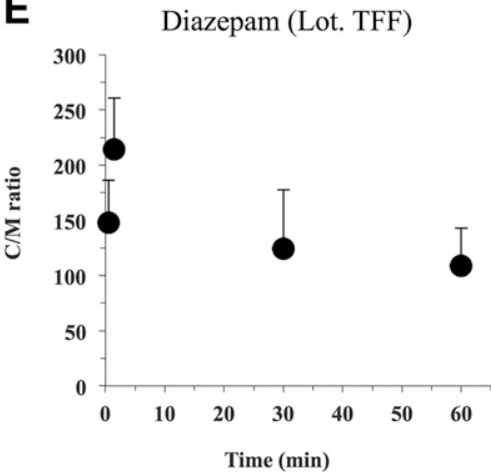

G

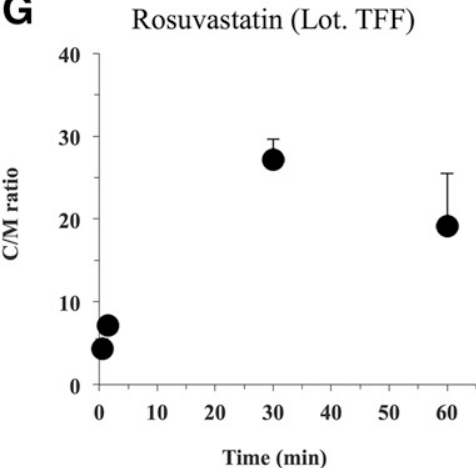

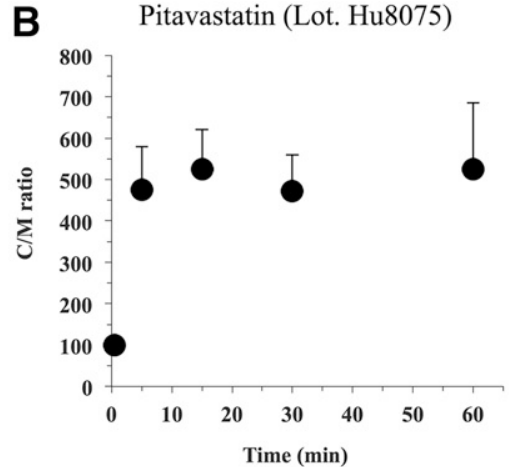

D Pravastatin (Lot. Hu8075)
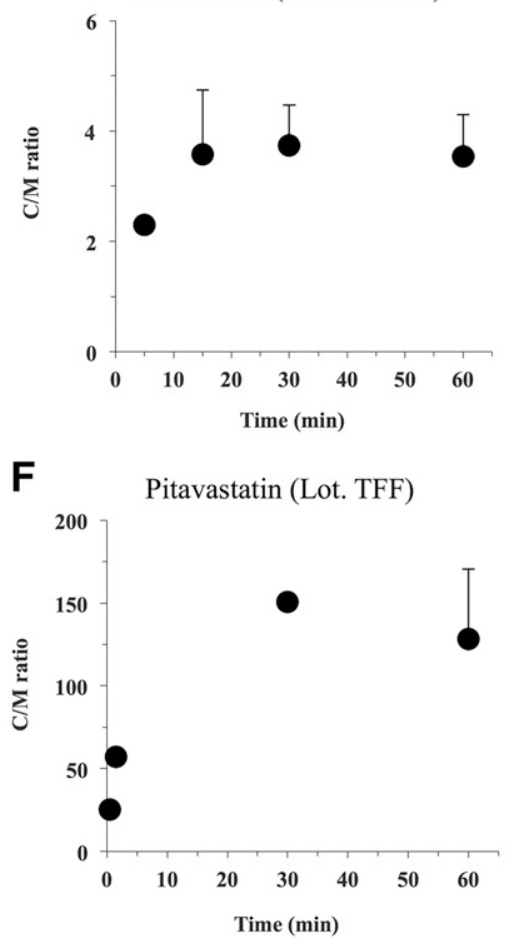

H

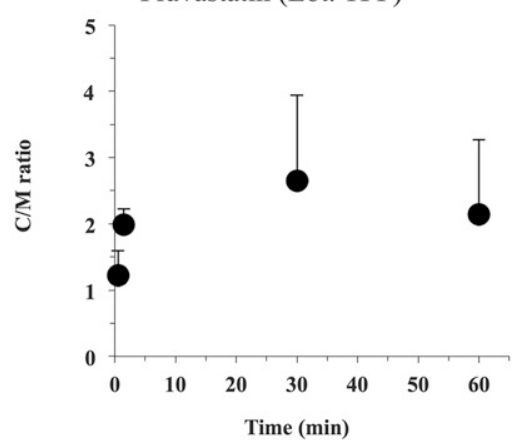

Fig. 2. Uptake of diazepam ( $1 \mu \mathrm{M}$; A and $\mathrm{E})$, pitavastatin $(1 \mu \mathrm{M}$; B and $\mathrm{F})$, rosuvastatin $(1 \mu \mathrm{M} ; \mathrm{C}$ and $\mathrm{G})$, and pravastatin $(1 \mu \mathrm{M} ; \mathrm{D}$ and $\mathrm{H})$ by human hepatocytes measured after incubation at $37^{\circ} \mathrm{C}$ for 0.5 60 minutes. (A-D) Cryopreserved human hepatocytes from a single donor (Lot Hu8075) were used. (E-H) Pooled cryopreserved human hepatocytes from 20 mixed-sex donors (Lot TFF) were used. The data are presented as mean + S.D. $(n=3)$. 
TABLE 4

$\mathrm{K}_{\mathrm{p}, \mathrm{uu}, \mathrm{ss}}$ and $\mathrm{f}_{\mathrm{T}, \mathrm{cell}, \mathrm{ss}}$ in human hepatocytes

Values are shown as the mean \pm S.D. $(n=3)$.

\begin{tabular}{|c|c|c|c|c|c|}
\hline \multirow[t]{2}{*}{ Drug } & \multirow[t]{2}{*}{ Lot } & \multicolumn{2}{|c|}{ C/M Ratio ${ }^{c}$} & \multirow[t]{2}{*}{$\mathrm{K}_{\mathrm{p}, \mathrm{uu}, \mathrm{ss}}{ }^{d}$} & \multirow[t]{2}{*}{$\mathrm{f}_{\mathrm{T}, \text { cell, ss }} d$} \\
\hline & & $37^{\circ} \mathrm{C}$ & On ice & & \\
\hline \multirow[t]{2}{*}{ Diazepam } & $\mathrm{Hu} 8075^{a}$ & $216 \pm 20$ & $181 \pm 38$ & $1.19 \pm 0.51$ & $0.00553 \pm 0.00115$ \\
\hline & $\mathrm{TFF}^{b}$ & $124 \pm 53$ & $303 \pm 22$ & $0.409 \pm 0.247$ & $0.00330 \pm 0.00024$ \\
\hline \multirow[t]{2}{*}{ Pitavastatin } & $\mathrm{Hu} 8075^{a}$ & $471 \pm 88$ & $35.2 \pm 2.6$ & $13.4 \pm 2.7$ & $0.0284 \pm 0.0021$ \\
\hline & $\mathrm{TFF}^{b}$ & $150 \pm 2.6$ & $21.8 \pm 3.2$ & $6.92 \pm 1.02$ & $0.0460 \pm 0.0068$ \\
\hline \multirow[t]{2}{*}{ Rosuvastatin } & $\mathrm{Hu} 8075^{a}$ & $52.2 \pm 8.6$ & $4.51 \pm 0.41$ & $11.6 \pm 2.2$ & $0.222 \pm 0.020$ \\
\hline & $\mathrm{TFF}^{b}$ & $27.2 \pm 2.5$ & $4.28 \pm 0.53$ & $6.36 \pm 1.06$ & $0.234 \pm 0.029$ \\
\hline \multirow[t]{2}{*}{ Pravastatin } & $\mathrm{Hu} 8075^{a}$ & $3.73 \pm 0.73$ & $1.84 \pm 0.12$ & $2.03 \pm 0.54$ & $0.545 \pm 0.035$ \\
\hline & $\mathrm{TFF}^{b}$ & $2.65 \pm 1.29$ & $2.07 \pm 0.64$ & $1.28 \pm 0.89$ & $0.484 \pm 0.151$ \\
\hline
\end{tabular}

${ }^{a}$ Isolated cryopreserved human hepatocytes (Lot Hu8075) were incubated with diazepam $(0.2 \mu \mathrm{M})$, pitavastatin $(0.1 \mu \mathrm{M})$, rosuvastati $(0.1 \mu \mathrm{M})$, and pravastatin $(0.2 \mu \mathrm{M})$.

${ }^{b}$ Pooled cryopreserved human hepatocytes from 20 mixed-sex donors (Lot TFF) were incubated with diazepam $(1 \mu \mathrm{M})$, pitavastatin $(0.5$ $\mu \mathrm{M})$, rosuvastatin $(0.5 \mu \mathrm{M})$, and pravastatin $(1 \mu \mathrm{M})$.

${ }^{\circ} \mathrm{C} / \mathrm{M}$ ratios at $37^{\circ} \mathrm{C}$ and on ice were calculated using the uptake data at 30 minutes and 60 minutes, respectively (Fig. 2).

${ }^{d}$ The $\mathrm{K}_{\mathrm{p} \text {,uu,ss }}$ and $\mathrm{f}_{\mathrm{T}, \text { cell,ss }}$ were calculated from $\mathrm{C} / \mathrm{M}$ ratios using eqs. 2 and 3, respectively.

pitavastatin, rosuvastatin, and pravastatin were approximately 11,13 , and 6.7, respectively (Table 2), confirming that these statins were concentrated in the hepatocytes by an active transport system. The obtained $\mathrm{f}_{\mathrm{T}, \text { cell,ss }}$ values for pitavastatin, rosuvastatin, and pravastatin were approximately $0.038,0.15$, and 0.60 , respectively.

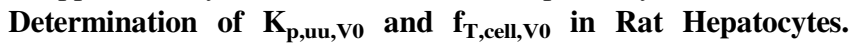
Subsequently, based on a method reported previously (Yabe et al., 2011), the kinetic parameters $\left(\mathrm{V}_{\max }, \mathrm{K}_{\mathrm{m}}\right.$, and $\left.\mathrm{PS}_{\mathrm{dif}}\right)$ for pitavastatin, rosuvastatin, and pravastatin were determined by fitting eq. 4 to their initial uptake rate. The results are shown in Eadie-Hofstee plots (Supplemental Fig. 2). The obtained $\mathrm{K}_{\mathrm{p}, \mathrm{uu}, \mathrm{v} 0}$ values for pitavastatin, rosuvastatin, and pravastatin were approximately 56, 51, and 8.6, respectively (Table 3 ). The calculated $\mathrm{f}_{\mathrm{T}, \text { cell, } \mathrm{V} 0}$ for pitavastatin, rosuvastatin, and pravastatin were approximately $0.17,0.65$, and 0.69, respectively.

Determination of $\mathbf{K}_{\mathrm{p}, \mathrm{uu}, \mathrm{ss}}$ and $\mathbf{f}_{\mathbf{T}, \mathrm{cell} \text {,ss }}$ in Human Hepatocytes. We investigated the time-dependent uptake of diazepam, pitavastatin, rosuvastatin, and pravastatin by human hepatocytes prepared from single donor (Lot Hu8075) (Fig. 2, A-D) and pooled human hepatocytes from 20 mixed-sex donors (Lot TFF) (Fig. 2, E-H). The uptake of all these statins increased over time and reached a steady state within 60 minutes, whereas that of diazepam reached a peak instantaneously. On ice, the $\mathrm{C} / \mathrm{M}$ ratios for pitavastatin, rosuvastatin, and pravastatin were reduced, whereas that for diazepam was not dependent on temperature
(Table 4). Although the $\mathrm{K}_{\mathrm{p}, \mathrm{uu}, \mathrm{ss}}$ for diazepam was approximately 1 (1.2 and 0.41 ), the values were 13 and 6.9 for pitavastatin, 12 and 6.4 for rosuvastatin, and 2.0 and 1.3 for pravastatin in cells from Lot Hu8075 and Lot TFF, respectively (Table 4 ). The obtained $\mathrm{f}_{\mathrm{T}, \text { cell, ss }}$ values were approximately 0.028 and 0.046 for pitavastatin, 0.22 and 0.23 for rosuvastatin, and 0.55 and 0.48 for pravastatin in cells from Lot $\mathrm{Hu} 8075$ and Lot TFF, respectively.

Determination of $\mathbf{K}_{\mathrm{p}, \mathrm{uu}, \mathrm{vo}}$ and $\mathbf{f}_{\mathrm{T}, \mathrm{cell}, \mathrm{vo}}$ in Human Hepatocytes. Based on a method reported previously (Yabe et al., 2011), the kinetic parameters $\left(\mathrm{V}_{\mathrm{max}}, \mathrm{K}_{\mathrm{m}}\right.$, and $\left.\mathrm{PS}_{\mathrm{dif}}\right)$ for pitavastatin and rosuvastatin were determined by fitting eq. 4 to their initial uptake rate by cells from Lot Hu8075 (Supplemental Fig. 3, A and B) and Lot TFF (Supplemental Fig. 3 , D and $\mathrm{E}$ ); the kinetic parameters of pravastatin could be determined in cells from Lot Hu8075 (Supplemental Fig. 3C), but not from Lot TFF, because a saturation of the uptake of pravastatin was not observed clearly within the concentration range of $0.5-300 \mu \mathrm{M}$.

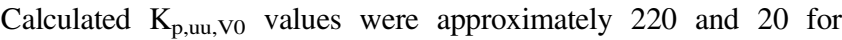
pitavastatin; 200 and 3.5 for rosuvastatin in cells from Lot Hu8075 and Lot TFF, respectively; and 55 for pravastatin in cells from Lot Hu8075 (Table 5), which were higher in cells from Lot Hu8075 than from Lot TFF. Calculated $\mathrm{f}_{\mathrm{T} \text {,cell,vo }}$ values were approximately 0.47 and 0.13 for pitavastatin; 3.8 and 0.13 for rosuvastatin in cells from Lot $\mathrm{Hu} 8075$ and Lot TFF, respectively; and 15 for pravastatin in cells from Lot $\mathrm{Hu} 8075$, although $\mathrm{f}_{\mathrm{T}, \text { cell }}$ should theoretically be less than 1 . Thus, the

TABLE 5

Kinetic parameters for the initial uptake of pitavastatin, rosuvastatin, and pravastatin in human hepatocytes

Values are shown as the mean \pm S.D.

\begin{tabular}{|c|c|c|c|c|c|c|c|}
\hline Drug & Lot & $\mathrm{V}_{\max }$ & $\mathrm{K}_{\mathrm{m}}$ & $\mathrm{V}_{\max } / \mathrm{K}_{\mathrm{m}}$ & $\mathrm{PS}_{\text {dif }}$ & $\mathrm{K}_{\mathrm{p}, \mathrm{uu}, \mathrm{vo}}{ }^{d}$ & $\mathrm{f}_{\mathrm{T}, \mathrm{cell}, \mathrm{V} 0}{ }^{d}$ \\
\hline & & $\mathrm{pmol} / \mathrm{min} / 10^{6}$ Cells & $\mu \mathrm{M}$ & $\mu \mathrm{L} / \mathrm{min} / 10^{6}$ Cells & $\mu \mathrm{L} / \mathrm{min} / 10^{6}$ Cells & & \\
\hline \multirow[t]{2}{*}{ Pitavastatin } & $\mathrm{Hu} 8075^{a}$ & $403 \pm 84$ & $4.77 \pm 1.80$ & $84.5 \pm 36.4$ & $0.388 \pm 0.912$ & $219 \pm 521$ & $0.465 \pm 1.110$ \\
\hline & $\mathrm{TFF}^{b}$ & $148 \pm 66.1$ & $1.78 \pm 1.04$ & $83.1 \pm 61.1$ & $4.36 \pm 0.70$ & $20.1 \pm 14.4$ & $0.134 \pm 0.096$ \\
\hline \multirow[t]{2}{*}{ Rosuvastatin } & $\mathrm{Hu} 8075^{a}$ & $198 \pm 50$ & $21.5 \pm 7.8$ & $9.21 \pm 4.07$ & $0.0462 \pm 0.1547$ & $200 \pm 673$ & $3.83 \pm 12.91$ \\
\hline & $\mathrm{TFF}^{b}$ & $23.0 \pm 8.6$ & $4.49 \pm 1.72$ & $5.12 \pm 2.75$ & $2.07 \pm 0.279$ & $3.47 \pm 1.41$ & $0.128 \pm 0.053$ \\
\hline Pravastatin & $\begin{array}{l}\text { Hu} 8075^{a} \\
\text { TFF }\end{array}$ & $93.8 \pm 56.0$ & $127 \pm 81$ & $\begin{array}{c}0.739 \pm 0.645 \\
\text { Not determined }^{c}\end{array}$ & $0.0137 \pm 0.0922$ & $54.8 \pm 363.7$ & $14.7 \pm 97.5$ \\
\hline
\end{tabular}

${ }^{a}$ The initial uptake rate in isolated cryopreserved human hepatocytes (Lot Hu8075) was calculated from the uptake of $\left[{ }^{3} \mathrm{H}\right]$ pitavastatin, $\left[{ }^{3} \mathrm{H}\right] \mathrm{rosuvastatin}$, and $\left[{ }^{3} \mathrm{H}\right]$ pravastatin for $0.5-2.0$ minutes. Kinetic parameters are obtained by fitting to the data at several concentrations $(0.1,0.3,1,3,10,30$, and $100 \mu \mathrm{M}$ for pitavastatin; $0.1,0.3,1,3,10,30$, and $300 \mu \mathrm{M}$ for rosuvastatin; 1, 3, 100, and $300 \mu \mathrm{M}$ for pravastatin; Supplemental Fig. 3, A-C) using eq. 4 .

${ }^{b}$ The initial uptake rate in pooled cryopreserved human hepatocytes from 20 mixed-sex donors (Lot TFF) was calculated from the uptake of $\left[{ }^{3} \mathrm{H}\right]$ pitavastatin and $\left[{ }^{3} \mathrm{H}\right]$ rosuvastatin for $0.5-1.5$ minutes. Kinetic parameters are obtained by fitting to the data at several concentrations $(0.1,0.3,1,3,10,30$, and $100 \mu \mathrm{M}$ for pitavastatin;

$0.1,0.3,1,3,10,30$, and $300 \mu \mathrm{M}$ for rosuvastatin; Supplemental Fig. 3, D and E) using eq. 4.

${ }^{c}$ Not determined in Lot TFF because a concentration $(0.5-300 \mu \mathrm{M})$-dependent saturation of the uptake of pravastatin was not observed clearly.

${ }^{d}$ The $\mathrm{K}_{\mathrm{p}, \mathrm{uu}, \mathrm{V} 0}$ and $\mathrm{f}_{\mathrm{T}, \mathrm{cell}, \mathrm{V} 0}$ were calculated using eqs. 5 and 6 , respectively. $\mathrm{C} / \mathrm{M}$ ratios at $37^{\circ} \mathrm{C}$ (Table 4) were used for the calculation of the $\mathrm{f}_{\mathrm{T}, \mathrm{cell}, \mathrm{V} 0}$ 
A

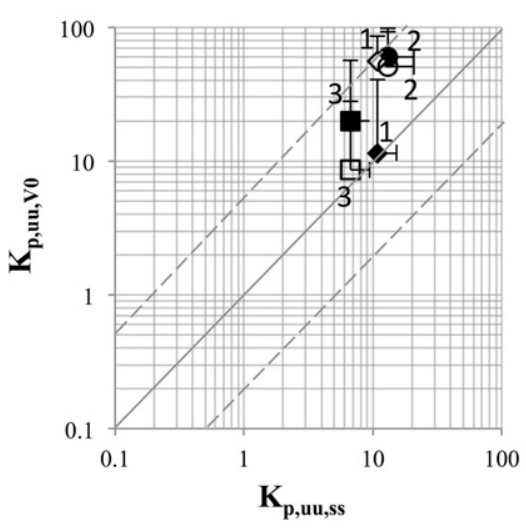

C

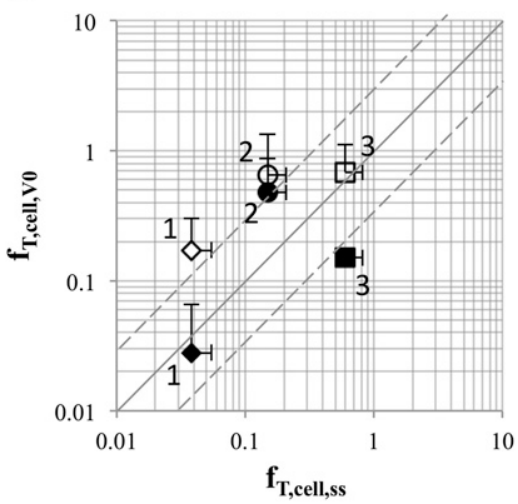

B

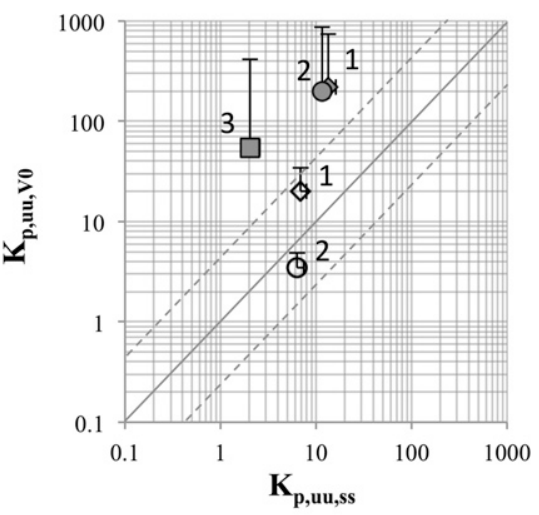

D

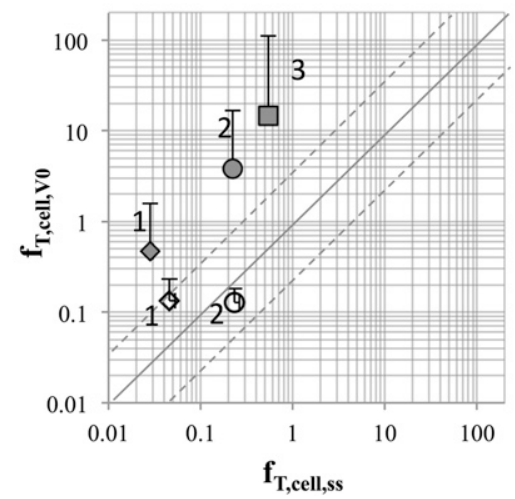

Fig. 3. Comparison of $\mathrm{K}_{\mathrm{p} \text {,u }}$ and $\mathrm{f}_{\mathrm{T} \text {, cell }}$ for three statins in rat and human hepatocytes obtained by two different methods. (A and $\mathrm{C}$ ) $\mathrm{K}_{\mathrm{p}, \mathrm{uu}, \mathrm{V} 0}$ and $\mathrm{f}_{\mathrm{T} \text {,cell,vo }}$ in rat hepatocytes derived from a previous report (Yabe et al., 2011) are plotted against $\mathrm{K}_{\mathrm{p} \text {,uu,ss }}$ and $\mathrm{f}_{\mathrm{T}, \text { cell,ss }}$ obtained in the present study as closed symbols. $\mathrm{K}_{\mathrm{p}, \mathrm{uu}, \mathrm{V} 0}$ and $\mathrm{f}_{\mathrm{T}, \mathrm{cell}} \mathrm{V} \mathrm{V}$ obtained in the present study are plotted against $\mathrm{K}_{\mathrm{p}, \mathrm{uu}, \mathrm{ss}}$ and $\mathrm{f}_{\mathrm{T} \text {,cell,ss }}$ as open symbols. ( $B$ and D) $K_{p, u u, v o}$ and $f_{T, \text { cell,vo }}$ in human hepatocytes from a single donor (Lot Hu8075) are plotted against $\mathrm{K}_{\mathrm{p}, \mathrm{uu}, \mathrm{ss}}$ and $\mathrm{f}_{\mathrm{T} \text {,cell,ss }}$ obtained in the present study as gray symbols. $\mathrm{K}_{\mathrm{p} \text {,uu,vo }}$ and $\mathrm{f}_{\mathrm{T}, \text { cell,vo }}$ in pooled human hepatocytes from 20 gender donors (Lot TFF) are plotted against $\mathrm{K}_{\mathrm{p} \text {,uu,ss }}$ and $\mathrm{f}_{\mathrm{T}, \text { cell,ss }}$ as open symbols. 1 , pitavastatin; 2, rosuvastatin; 3 , pravastatin. Solid and dashed lines denote unity and threefold boundaries, respectively. The data are presented as mean + S.D. for the $x$ - and $y$-axis $(n=3)$. values of $\mathrm{K}_{\mathrm{p} \text {,uu, vo }}$ and $\mathrm{f}_{\mathrm{T} \text {,cell,vo }}$ exhibited greater differences between lots.

Comparison of $\mathbf{K}_{\mathrm{p}, \mathrm{uu}}$ and $\mathbf{f}_{\mathrm{T}, \mathrm{cell}}$ Obtained by Different Methods. In rat hepatocytes, $\mathrm{K}_{\mathrm{p}, \mathrm{uu}, \mathrm{vo}}$ values for pitavastatin, rosuvastatin, and pravastatin were, respectively, 5.1, 5.1, and 1.2 times those for $\mathrm{K}_{\mathrm{p} \text {,uu,ss }}$ (Fig. 3A). By contrast, in human hepatocytes (Lot Hu8075), $\mathrm{K}_{\mathrm{p} \text {,uu,Vo }}$ values for pitavastatin, rosuvastatin, and pravastatin were, respectively, 16, 17, and 43 times those for $\mathrm{K}_{\mathrm{p} \text {,uu,ss }}$ (Fig. 3B). The differences between $\mathrm{K}_{\mathrm{p}, \mathrm{uu}, \mathrm{Vo}}$ and $\mathrm{K}_{\mathrm{p}, \mathrm{uu}, \mathrm{ss}}$ in human hepatocytes from Lot TFF were smaller than those in Lot Hu8075: $\mathrm{K}_{\mathrm{p}, \mathrm{uu}, \mathrm{V} 0}$ values for pitavastatin and rosuvastatin were, respectively, 2.9 and 0.55 times those for $\mathrm{K}_{\mathrm{p}, \mathrm{uu}, \mathrm{ss}}$ in cells from Lot TFF (Fig. 3B).

The $\mathrm{f}_{\mathrm{T}, \text { cell,vo }}$ values tended to be higher than $\mathrm{f}_{\mathrm{T} \text {, cell,ss }}$ in both rat (Fig. 3C) and human hepatocytes (Fig. 3D), except for rosuvastatin in human hepatocytes (Lot TFF). Both $\mathrm{K}_{\mathrm{p} \text {,uu,vo }}$ and $\mathrm{f}_{\mathrm{T} \text {,cell,vo values thus exhibited }}$ quite larger interlot and interexperimental variabilities compared with $\mathrm{K}_{\mathrm{p} \text {,uu,ss }}$ and $\mathrm{f}_{\mathrm{T} \text {,cell,ss }}$ values (comparison between Tables 2 and 3 for rats and Tables 4 and 5 for humans).

Comparison of $\mathbf{f}_{\mathrm{T}, \mathrm{cell}}$ with the Measured Unbound Fraction in Human Liver Homogenates. For diazepam, pitavastatin, rosuvastatin, and pravastatin, the measured unbound fractions in human liver homogenates $\left(\mathrm{f}_{\mathrm{T} \text {,homogenate }}\right.$ ) were measured using equilibrium dialysis (Table 6). The $\mathrm{f}_{\mathrm{T} \text {,homogenate }}$ values for these drugs obtained at $37^{\circ} \mathrm{C}$ $\left(\mathrm{f}_{\mathrm{T}, \text { homogenate, } 37^{\circ} \mathrm{C}}\right)$ were close to those obtained on ice $\left(\mathrm{f}_{\mathrm{T}, \text { homogenate, on ice }}\right)$.

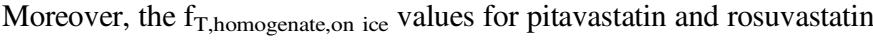
were comparable to those for $\mathrm{f}_{\mathrm{T} \text {,cell,ss }}$ (Table 4); the difference between $\mathrm{f}_{\mathrm{T} \text {,homogenate,on ice }}$ and $\mathrm{f}_{\mathrm{T} \text {,cell,ss }}$ for pravastatin was within threefold, whereas there was a larger discrepancy between $\mathrm{f}_{T, \text { homogenate,on ice }}$ and $\mathrm{f}_{\mathrm{T} \text {,cell,ss }}$ for diazepam.
Measurement of the $\Delta \Psi$ Using TPP $^{+}$. To evaluate whether $\Delta \Psi$ might affect the ratio of $\mathrm{PS}_{\mathrm{dif}, \text { inf }} / \mathrm{PS}_{\mathrm{dif} \text {,eff }}$ and, accordingly, $\mathrm{K}_{\mathrm{p} \text {,uu }}$, the time-dependent uptake of $\mathrm{TPP}^{+}$was examined in human hepatocytes under physiologic conditions and with amphotericin $\mathrm{B}$, which is reported to abolish $\Delta \Psi$ specifically by 10 -minute incubation with isolated rat hepatocytes (Saito et al., 1992). The C/M ratio of $\mathrm{TPP}^{+}$ gradually increased over time and reached the steady state between 30 and 60 minutes (Fig. 4). On ice, the $\mathrm{C} / \mathrm{M}$ ratio of $\mathrm{TPP}^{+}$was significantly smaller than that at $37^{\circ} \mathrm{C}$. In addition, in the presence of amphotericin $\mathrm{B}$, the $\mathrm{C} / \mathrm{M}$ ratio of $\mathrm{TPP}^{+}$was decreased significantly at $37^{\circ} \mathrm{C}$ compared with the condition without amphotericin $\mathrm{B}$, whereas the $\mathrm{C} / \mathrm{M}$ ratio on ice was not significantly changed with amphotericin $\mathrm{B}$ (Fig. 4). The $\mathrm{C} / \mathrm{M}$ ratio $\left(37^{\circ} \mathrm{C}\right)$ in the presence of amphotericin $\mathrm{B}$ at 60 minutes was lower than that at 30 minutes, suggesting some additional effects of amphotericin $B$ (i.e., cytotoxicity) other than the loss of the $\Delta \Psi$. Therefore, based on the obtained data at 30 minutes and

TABLE 6

$\mathrm{f}_{\mathrm{T}, \text { homogenate }}$ in human liver homogenate

Values are shown as the mean \pm S.D. $(n=3)$

\begin{tabular}{lccc}
\hline \multirow{2}{*}{ Drug } & $37^{\circ} \mathrm{C}$ & $\mathrm{f}_{\mathrm{T}, \text { homogenate }}$ \\
\cline { 2 - 4 } & $0.0259 \pm 0.0018$ & $0.0242 \pm 0.0016$ & $1.07 \pm 0.10$ \\
\cline { 2 - 4 } Diazepam & $0.0301 \pm 0.0017$ & $0.0344 \pm 0.0018$ & $0.875 \pm 0.067$ \\
Pitavastatin & $0.237 \pm 0.037$ & $0.206 \pm 0.025$ & $1.15 \pm 0.23$ \\
Rosuvastatin & $0.183 \pm 0.022$ & $0.167 \pm 0.020$ & $1.10 \pm 0.19$ \\
Pravastatin & & & \\
\hline
\end{tabular}




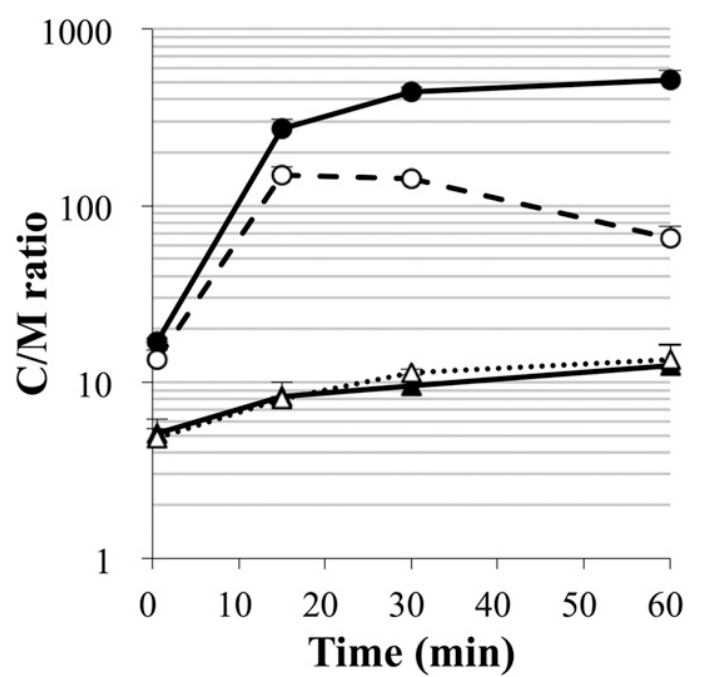

Fig. 4. Uptake of $\mathrm{TPP}^{+}$by human hepatocytes measured after incubation at $37^{\circ} \mathrm{C}$ (circles) or on ice (triangles) for 0.5-60 minutes. Hepatocytes were incubated with $3 \mu \mathrm{M} \mathrm{TPP}{ }^{+}$(closed symbols) or both $3 \mu \mathrm{M} \mathrm{TPP}^{+}$and $20 \mu \mathrm{M}$ amphotericin B (open symbols). Pooled cryopreserved human hepatocytes from 50 mixed-sex donors (Lot HUE50C) were used. The data are presented as mean + S.D. $(n=3)$.

eq. $10, \Delta \Psi$ values were calculated to be approximately $-30 \mathrm{mV}$ at $37^{\circ} \mathrm{C}$ and $5 \mathrm{mV}$ on ice (Table 7).

Using $\Phi[=\exp (\mathrm{z} \cdot \mathrm{F} \cdot \Delta \Psi / \mathrm{R} / \mathrm{T})]$ calculated from $\Delta \Psi$ (Supplemental Equation 5) and physicochemical parameters calculated for statins

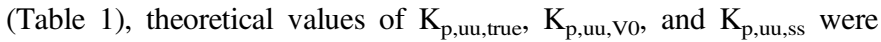
calculated by Supplemental Equations 6, 8, and 11, respectively (Table 8).

Furthermore, we aimed to understand better the quantitative relationship between $K_{p, u u, t r u e}$ and experimentally obtained $K_{p, u u, s s}$ and $K_{p, u u, v o}$ for statins based on theoretical equations that consider the insidenegative $\Delta \Psi$. Using $\Delta \Psi$ (Table 7) and several physicochemical parameters of statins (Table 1), the ratios of $\mathrm{K}_{\mathrm{p} \text {,uu, } \mathrm{V} /} / \mathrm{K}_{\mathrm{p} \text {,uu,true }}$ and $\mathrm{K}_{\mathrm{p}, \text { uu,ss }} / \mathrm{K}_{\mathrm{p} \text {,uu,true }}\left(\mathrm{R}_{\mathrm{V} 0 / \text { true }}\right.$ or $\left.\mathrm{R}_{\mathrm{ss} / \text { true }}\right)$ can be described as follows:

$$
\begin{aligned}
R_{V 0 / \text { true }}=K_{p, \text { uu }, V 0} / K_{p, \text { uu,true }} & =\frac{\Phi \cdot \lambda \cdot f_{i, \text { ion }}+f_{i, \text { uion }},}{\lambda \cdot f_{o, \text { ion }}+f_{o, \text { uion }}}, \\
R_{s s / \text { true }}=K_{p, \text { uu }, \text { ss }} / K_{p, \text { uu }, \text { true }} & =\frac{\lambda \cdot f_{i, \text { ion }}+f_{i, \text { uion }}}{\lambda \cdot f_{o, \text { ion }}+f_{o, \text { uion }}},
\end{aligned}
$$

where $\mathrm{f}_{\mathrm{i} \text {,ion }}$ and $\mathrm{f}_{\mathrm{i} \text {,uion }}$ are fractions of the ionized and nonionized forms of the drug in hepatocytes, respectively, with the use of intracellular $\mathrm{pH}$

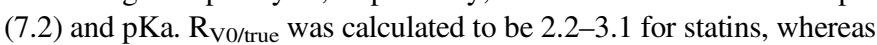
$\mathrm{R}_{\mathrm{ss} / \text { true }}$ was $0.85-1.2$ (Table 8). Figure 5 also shows that simulated $\mathrm{R}_{\mathrm{ss} / \text { true }}$ was closer to 1 than $\mathrm{R}_{\mathrm{V} 0 / \text { true }}$ when $\lambda$ values for pitavastatin, rosuvastatin, and pravastatin were approximately $0.028,0.011$, and 0.19 , respectively (Table 1). Furthermore, experimentally obtained $\mathrm{K}_{\mathrm{p}, \mathrm{uu}, \mathrm{V} 0}$ and $\mathrm{K}_{\mathrm{p}, \mathrm{uu}, \mathrm{ss}}$ for statins were corrected using the calculated $\mathrm{R}_{\mathrm{V} 0 / \text { true }}$ and $\mathrm{R}_{\mathrm{ss} / \text { true }}$ values (Table 8) and eqs. 14 and 15:

TABLE 7

Theoretical calculation of the $\Delta \Psi$ using the measured $\mathrm{C} / \mathrm{M}$ ratios of $\mathrm{TPP}^{+}$ Values are shown as the mean \pm S.D. $(n=4)$.

\begin{tabular}{lccrrr}
\hline \multirow{2}{*}{ Temperature } & \multicolumn{2}{c}{ C/M Ratio } & & \multicolumn{1}{c}{$\Delta \Psi^{a}$} & \multirow{2}{*}{$\Phi^{a}$} \\
\cline { 2 - 3 } & \multicolumn{1}{c}{ AMB } & \multicolumn{1}{c}{$+\mathrm{AMB}$} & & \multicolumn{1}{c}{$\mathrm{mV}$} & \\
\hline $37^{\circ} \mathrm{C}$ & $442.7 \pm 31.1$ & $142.4 \pm 4.3$ & & $-30.22 \pm 2.04$ & $3.109 \pm 0.237$ \\
On ice & $9.5 \pm 1.4$ & $11.3 \pm 0.5$ & & $4.97 \pm 4.12$ & $0.840 \pm 0.128$ \\
\hline
\end{tabular}

${ }^{a} \Delta \Psi$ and $\Phi$ were calculated using eq. 10 and Supplemental Equation 5, respectively.
TABLE 8

Theoretical calculation of $\mathrm{K}_{\mathrm{p} \text {,uu,true }}, \mathrm{K}_{\mathrm{p}, \mathrm{uu}, \mathrm{V} 0}$, and $\mathrm{K}_{\mathrm{p} \text {,uu,ss }}$ using the calculated $\Delta \Psi$

\begin{tabular}{clccccc}
\hline Drug & Lot & $\mathrm{K}_{\mathrm{p}, \text { uu,true }}{ }^{a}$ & $\mathrm{~K}_{\mathrm{p}, \text { uu,vo }}{ }^{a}$ & $\mathrm{~K}_{\mathrm{p}, \mathrm{uu}, \mathrm{ss}}{ }^{a}$ & $\mathrm{R}_{\mathrm{V} \text { /true }}{ }^{b}$ & $\mathrm{R}_{\mathrm{ss} / \text { true }}{ }^{b}$ \\
\hline \multirow{2}{*}{ Pitavastatin } & Hu8075 & 90.7 & 198 & 106 & 2.18 & 1.17 \\
& $\mathrm{TFF}$ & 8.35 & 18.3 & 9.75 & 2.18 & 1.17 \\
Rosuvastatin & $\mathrm{Hu} 8075$ & 72.4 & 199 & 71.9 & 2.74 & 0.994 \\
& $\mathrm{TFF}$ & 1.26 & 3.45 & 1.25 & 2.74 & 0.994 \\
Pravastatin & $\mathrm{Hu} 8075$ & 17.9 & 54.5 & 15.2 & 3.05 & 0.850 \\
& TFF & Not calculated $^{c}$ & & & & \\
& & & & &
\end{tabular}

${ }^{a}$ Theoretical values of $\mathrm{K}_{\mathrm{p}, \mathrm{uu}, \text { true }}, \mathrm{K}_{\mathrm{p}, \mathrm{uu}, \mathrm{V} 0}$, and $\mathrm{K}_{\mathrm{p}, \mathrm{uu}, \mathrm{ss}}$ were calculated by Supplemental Equations 6,8 , and 11 , respectively. The $\mathrm{f}_{\mathrm{i}, \text { ion }}, \mathrm{f}_{\mathrm{o}, \text { ion }}, \mathrm{f}_{\mathrm{i}, \text { uion }}, \mathrm{f}_{\mathrm{o} \text {,uion }}, \lambda$ (Table 1 ), $\mathrm{V}_{\max } / \mathrm{K}_{\mathrm{m}}$ (Table 5), and $\mathrm{PS}_{\text {dif,inf,uion }}$ in each lot of human hepatocytes determined by $\mathrm{f}_{\mathrm{o}, \text { ion }}, \mathrm{f}_{\mathrm{o}, \text { uion }}, \lambda$, and $\mathrm{PS}_{\mathrm{dif}}$ (Table 5), according to eq. 7 , were used for the calculation.

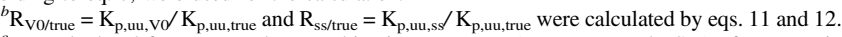

${ }^{c}$ Not calculated for Lot TFF because kinetic parameters $\left(\mathrm{K}_{\mathrm{m}}, \mathrm{V}_{\mathrm{max}}\right.$, and $\left.\mathrm{PS}_{\mathrm{dif}}\right)$ of pravastatin were not determined (Table 5).

$$
\begin{gathered}
K_{p, u u, V 0, \text { corrected }}=K_{p, u u, V 0} / R_{V 0 / \text { true }} \\
K_{p, u u, s s, \text { corrected }}=K_{p, u u, s s} / R_{s s / \text { true }}
\end{gathered}
$$

$\mathrm{K}_{\mathrm{p} \text {,uu,V0,corrected }}$ in rat hepatocytes approached $\mathrm{K}_{\mathrm{p}, \mathrm{uu}, \mathrm{ss}, \mathrm{corrected}}$ (Fig. 6A) compared with uncorrected $\mathrm{K}_{\mathrm{p}, \mathrm{uu}, \mathrm{Vo}}$ versus $\mathrm{K}_{\mathrm{p}, \mathrm{uu}, \mathrm{ss}}$ (Fig. $3 \mathrm{~A}$ ): the calculated

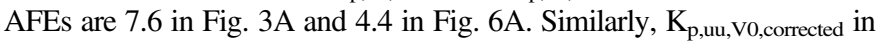
human hepatocytes approached corrected $\mathrm{K}_{\mathrm{p} \text {,uu,ss,corrected }}$ (Figs. $3 \mathrm{~B}$ and 6B): the calculated AFEs are 132 in Fig. 3B and 41 in Fig. 6B. However, $\mathrm{K}_{\mathrm{p}, \mathrm{uu}, \mathrm{V} \text {,corrected }}$ in Lot Hu8075, a single donor lot selected because of its relatively high uptake ability, remained larger than $\mathrm{K}_{\mathrm{p}, \mathrm{uu}, \mathrm{ss}, \text { corrected. }}$

\section{Discussion}

We previously proposed a method to estimate $\mathrm{K}_{\mathrm{p} \text {,uu,ss }}$ for anions in hepatocytes based on their steady-state $\mathrm{C} / \mathrm{M}$ ratio at $37^{\circ} \mathrm{C}$ and the $\mathrm{C} / \mathrm{M}$ ratio after suppressing active transport (Yamazaki et al., 1992; Shitara et al., 2013). Another method reported by Yabe et al. (2011) is to estimate $\mathrm{K}_{\mathrm{p} \text {,uu,vo }}$ based on initial uptake rates at various concentrations. $\mathrm{K}_{\mathrm{p} \text {,uu,ss }}$ values for pitavastatin, rosuvastatin, and pravastatin in rat and human hepatocytes, which were obtained with less interexperimental variation compared with $\mathrm{K}_{\mathrm{p}, \mathrm{uu}, \mathrm{V} 0}$ values in this study, tended to be

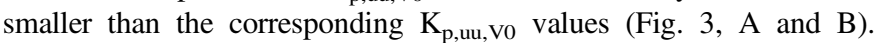
Considering the measured inside-negative $\Delta \Psi$ (Table 7) and subsequent asymmetric diffusional clearance for influx and efflux, $\mathrm{K}_{\mathrm{p}, \mathrm{uu}, \mathrm{V} 0 \text {,corrected }}$ in rat and human hepatocytes approached $\mathrm{K}_{\mathrm{p} \text {,uu,ss,corrected (Fig. 6). }}$

There exists a practical advantage of the method to obtain the $\mathrm{K}_{\mathrm{p} \text {,uu,ss }}$ value over the method to obtain the $K_{p, u u, v o}$ value. Interlot and interexperimental variabilities are much less for $\mathrm{K}_{\mathrm{p}, \mathrm{uu}, \mathrm{ss}}$ than for $\mathrm{K}_{\mathrm{p}, \mathrm{uu}, \mathrm{V} 0}$ (Tables 2-5), because uptake data at longer time (e.g., 30-60 minutes, almost at steady state) are enough to obtain $\mathrm{K}_{\mathrm{p} \text {,uu,ss, whereas initial }}$

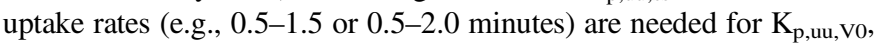
and such a method requires quite accurate techniques for rapid samplings.

In the extended clearance concept, $\mathrm{K}_{\mathrm{p} \text {,uu,true }}$ is described as in eq. 16 (Shitara et al., 2013):

$$
K_{p, \text { uu }, \text { true }}=\frac{P S_{a c t, i n f}+P S_{\text {dif }, \text { inf }}}{P S_{a c t, e f f}+P S_{\text {dif }, \text { eff }}+C L_{\text {int }, \text { met }}+C L_{\text {int }, \text { ille }}},
$$

where $\mathrm{PS}_{\mathrm{act}, \text { inf }}, \mathrm{PS}_{\mathrm{act}, \mathrm{eff}}, \mathrm{CL}_{\text {int,met }}$, and $\mathrm{CL}_{\text {int,bile }}$ represent the active influx clearance, the active efflux clearance, the intrinsic clearance for metabolism, and the intrinsic clearance for biliary excretion in an unchanged form, respectively. Based on eq. 16, a number of explanations can be considered for why $\mathrm{K}_{\mathrm{p}, \mathrm{uu}, \mathrm{V} 0}$ values for pitavastatin, rosuvastatin, and pravastatin tended to be larger than $\mathrm{K}_{\mathrm{p} \text {,uu,ss }}$ in both rat and human hepatocytes (Fig. 3, A and B). 

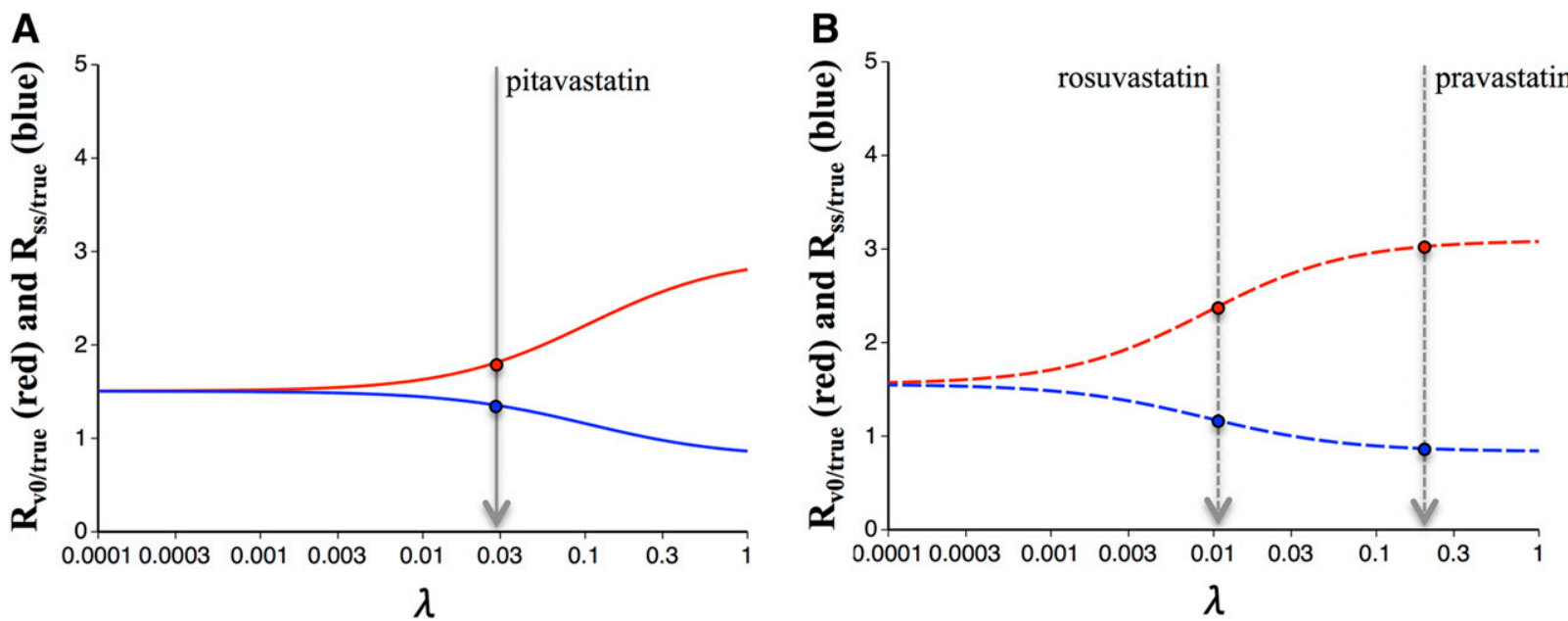

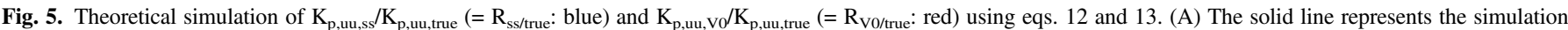

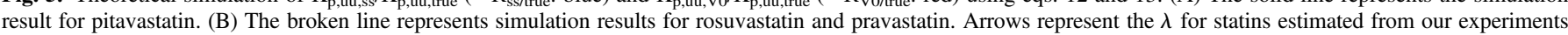
with Caco- 2 cells.

(i) As $\mathrm{PS}_{\mathrm{act}, \text { inf }}$ is estimated by initial uptake rate for the calculation

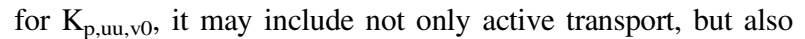
facilitated diffusion, which is also transporter mediated, but not by active (concentrated) transport. Thus, in this case, $\mathrm{K}_{\mathrm{p}, \mathrm{uu}, \mathrm{V} 0}$ can be larger than $\mathrm{K}_{\mathrm{p} \text {,uu,ss. }}$. However, in the case of statins, hepatic OATPs are thought to be major uptake transporters, and the impact of facilitated diffusion on their overall uptake may be negligible.

(ii) The existence of non-negligible metabolism during the measurement of steady-state uptake (30-60 minutes) of a drug may lead to smaller $\mathrm{K}_{\mathrm{p} \text {,uu,ss }}$ than $\mathrm{K}_{\mathrm{p} \text {,uu,vo values, because }}$ metabolism might be negligible during short incubation times ( $\sim 2$ minutes) for the measurement of initial uptake rates. Considering that pitavastatin, rosuvastatin, and pravastatin are generally classified as statins metabolized poorly in humans (Shitara and Sugiyama, 2006), it is unlikely that metabolism accounts for the overestimation of $\mathrm{K}_{\mathrm{p} \text {,uu,vo. However, a recent }}$ report suggested that pitavastatin undergoes lactonization by uridine 5'-diphospho-glucuronosyltransferases more extensively than other statins (Schirris et al., 2015), which may explain, at least in part, the overestimation of $\mathrm{K}_{\mathrm{p}, \mathrm{uu}, \mathrm{V} 0}$ compared with $\mathrm{K}_{\mathrm{p} \text {,uu,ss }}$ (Fig. 3, $\mathrm{A}$ and $\mathrm{B}$ ). In addition, pentenoic acid derivative was reported to be the major metabolite of rosuvastatin in rats (Nezasa et al., 2002; He et al., 2014). In our experiments using rat hepatocytes, the remaining amount of rosuvastatin after the 30 -minute incubation was $87 \%$ of the initial amount, whereas little loss of rosuvastatin was observed after the 60-minute incubation in human hepatocytes. Therefore, the contribution of metabolism to the elimination of rosuvastatin in rats might be larger than that in humans, and the metabolism of rosuvastatin in rat hepatocytes might only slightly influence the estimation of its $\mathrm{K}_{\mathrm{p} \text {,uu,ss }}$.

(iii) $\mathrm{PS}_{\text {act,eff }}$ and $\mathrm{CL}_{\text {int,bile }}$ cannot be fully estimated by the shortterm uptake of drugs. Thus, if a drug is a substrate of basolateral/ apical efflux transporters, $\mathrm{K}_{\mathrm{p}, \mathrm{uu}, \mathrm{Vo}}$ may be overestimated. The expression of apical efflux transporters [P-glycoprotein, multidrug resistance-associated protein 2 (MRP2), and breast cancer resistance protein] and basolateral efflux transporters (MRP3 and MRP4) was partly retained in cryopreserved human hepatocytes compared with fresh liver biopsies (Lundquist et al., 2014), which might contribute, at least in part, to the drug efflux from hepatocytes and lead to a discrepancy between $\mathrm{K}_{\mathrm{p} \text {,uu,vo }}$ and $\mathrm{K}_{\mathrm{p} \text {,uu,ss. }}$.

(iv) In most work, $\mathrm{PS}_{\mathrm{dif}, \text { inf }}$ and $\mathrm{PS}_{\mathrm{dif} \text {,eff }}$ are conventionally assumed to be equal for kinetic consideration of the cellular transport (Yabe et al., 2011), although $\mathrm{PS}_{\text {dif,eff might be larger }}$ than $\mathrm{PS}_{\mathrm{dif} \text {,inf }}$ in the case of anions because of the inside-negative $\Delta \Psi$ in normal cells. We calculated $\mathrm{K}_{\mathrm{p}, \mathrm{uu}, \mathrm{ss}}$ by taking

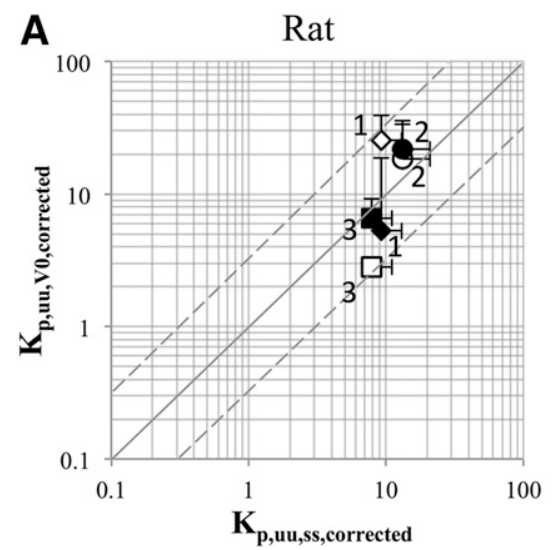

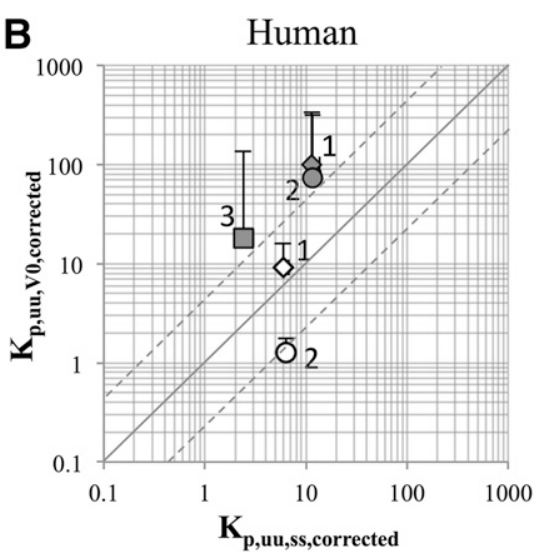

Fig. 6. Comparison of $\mathrm{K}_{\mathrm{p}, \mathrm{uu}, \mathrm{ss}, \text { corrected }}$ and $\mathrm{K}_{\mathrm{p}, \mathrm{uu}, \mathrm{V} \text {, corrected }}$ corrected by eqs. 14 and 15 using $\mathrm{R}_{\mathrm{ss} / \text { true }}$ and $\mathrm{R}_{\mathrm{V} 0 / \text { true }}$ (Table 8). (A) Closed symbols: original $K_{p, u u, v o}$ in rat hepatocytes were obtained from a previous report (Yabe et al., 2011). Open

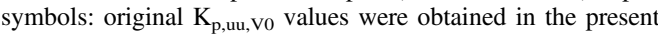
study. (B) Gray symbols: original $\mathrm{K}_{\mathrm{p}, \mathrm{uu}, \mathrm{v} \text { v values were obtained }}$ in human hepatocytes from a single donor (Lot Hu8075). Open symbols: original $\mathrm{K}_{\mathrm{p}, \mathrm{uu}, \mathrm{V} 0}$ values were obtained in pooled human hepatocytes from 20 mixed-sex donors (Lot. TFF). 1, pitavastatin; 2, rosuvastatin; 3 , pravastatin. Solid and dashed lines denote unity and threefold boundaries, respectively. The data are presented as mean + S.D. for the $x$ - and $y$-axis $(n=3)$. 
asymmetric $\mathrm{PS}_{\mathrm{dif}}$ into consideration with the assumption that $\Delta \Psi$ is almost abolished on ice, as we confirmed experimentally (Table 7). Conversely, to calculate $\mathrm{K}_{\mathrm{p}, \mathrm{uu}, \mathrm{v} 0}, \mathrm{PS}_{\mathrm{dif} \text {,eff }}$ is set to be the same as $\mathrm{PS}_{\mathrm{dif}, \text { inf }}$, as shown in Supplemental Equation 8 . Therefore, theoretically, $\mathrm{K}_{\mathrm{p} \text {,uu,vo }}$ should be larger than $\mathrm{K}_{\mathrm{p} \text {,uu,ss }}$ in the case of anions, which might mostly explain the observed discrepancy between $\mathrm{K}_{\mathrm{p} \text {,uu,ss }}$ and $\mathrm{K}_{\mathrm{p} \text {,uu,vo. }}$

In this study, two assumptions were made. First, $\mathrm{f}_{\mathrm{T}, \text { cell,ss }}$ is not affected by temperature; second, $\Delta \Psi$ is abolished on ice. To investigate the first assumption, we sought to evaluate whether $\mathrm{f}_{\mathrm{T}, \text { cell,ss }}$ was largely dependent on temperature, as mentioned in previous reports (Sugano et al., 2010; Shitara et al., 2013). We found that values for $\mathrm{f}_{\mathrm{T}, \text { homogenate,on ice }}$ were comparable with those for $\mathrm{f}_{\mathrm{T}, \text { homogenate } 37^{\circ} \mathrm{C}}$ (Table 6), which supports the first assumption, at least for the statins tested. In addition, $\mathrm{f}_{\mathrm{T}, \text { cell,ss }}$ for rosuvastatin and pitavastatin measured by equilibrium

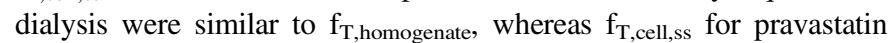
was larger than $\mathrm{f}_{\mathrm{T}, \text { homogenate }}$ (Tables 4 and 6), although the mechanism behind this has not yet been clarified. By contrast, $f_{T, \text { cell,V0 }}$ for rosuvastatin and pravastatin in human hepatocytes exceeded 1 with large S.D. (Table 5), suggesting that it might be difficult to obtain reliable values for $\mathrm{f}_{\mathrm{T} \text {,cell }}$ based on the rate of initial uptake. Indeed, Yabe et al. (2011) estimated $\mathrm{f}_{\mathrm{T}, \text { cell,vo }}$ for some drugs, including pravastatin, not by eq. 6 , but by using in silico prediction with $\log \mathrm{D}$ to obtain reasonable values for $\mathrm{f}_{\mathrm{T}, \text { cell, }} \mathrm{vo}$.

The second assumption was investigated using $\mathrm{TPP}^{+}$uptake studies with and without amphotericin B in human hepatocytes (Fig. 4), according to a method reported previously (Saito et al., 1992). Calculated $\Delta \Psi$ at $37^{\circ} \mathrm{C}$ was similar to reported values $(-35$ to $-39 \mathrm{mV}$ ) obtained in isolated rodent hepatocytes (Bradford et al., 1985; Edmondson et al., 1985; Fitz and Scharschmidt, 1987; Wondergem and Castillo, 1988; Weinman et al., 1989), and $\Delta \Psi$ was almost abolished on ice under steadystate conditions at 30 minutes (Table 7). Collectively, our assumptions are valid for anions.

For the estimation of $\mathrm{K}_{\mathrm{p}, \mathrm{uu}, \mathrm{ss}}$, ATP depletors such as rotenone were also used to stop the active uptake (Yamazaki et al., 1992); however, it is difficult to optimize experimental conditions for the exposure to ATP depletors to abolish the active uptake without affecting cell viability, and the effect of ATP depletion is often required to be insufficient to maintain viability (Yamazaki et al., 1993). Thus, this approach may lead to underestimation of $\mathrm{K}_{\mathrm{p} \text {,uu,ss }}$. The use of transporter inhibitors is another strategy to stop the active transport. However, before this, we should understand the major transport mechanism of the drugs to be tested, and confirm that the contribution of other transporters to the overall active uptake is negligible. In the case of statins, because $\mathrm{Na}^{+}$-taurocholate cotransporting polypeptide is known to partly play a role in their hepatic uptake (Bi et al., 2013), the inhibition of $\mathrm{Na}^{+}$-taurocholate cotransporting polypeptide in addition to OATPs is required; otherwise, insufficient inhibition of the hepatic uptake causes an underestimation of $\mathrm{K}_{\mathrm{p} \text {,uu,ss. }}$

In conclusion, $\mathrm{K}_{\mathrm{p} \text {,uu }}$ of statins were estimated in rat and human hepatocytes using two different methods based on steady-state uptake $\left(\mathrm{K}_{\mathrm{p}, \mathrm{uu}, \mathrm{ss}}\right)$ and initial uptake rate $\left(\mathrm{K}_{\mathrm{p}, \mathrm{uu}, \mathrm{v} 0}\right)$. Considering the insidenegative $\Delta \Psi$ and subsequent asymmetric diffusional clearance for influx and efflux, in theory, $\mathrm{K}_{\mathrm{p}, \mathrm{uu} \text {,ss }}$ should be similar to true $\mathrm{K}_{\mathrm{p} \text {,uu }}\left(\mathrm{K}_{\mathrm{p} \text {,uu,true }}\right)$, whereas $\mathrm{K}_{\mathrm{p} \text {,uu,Vo }}$ should be higher compared with $\mathrm{K}_{\mathrm{p} \text {,uu,true }}$ This can explain, at least in part, the discrepancies observed between $\mathrm{K}_{\mathrm{p}, \mathrm{uu}, \mathrm{ss}}$ and $\mathrm{K}_{\mathrm{p} \text {,uu,vo }}$ for statins in the present study. Using the estimated $\mathrm{K}_{\mathrm{p} \text {,uu }}$ value and the ratio of diffusional uptake to active uptake determined in vitro, we can mathematically describe the relationship among permeation clearances across the sinusoidal membrane of hepatocytes, which can be applied for the construction of a physiologically-based pharmacokinetic model.
Although our current approach should be valid from the viewpoint of kinetic theory, we will need to practically validate our method for the in vitro-in vivo extrapolation of $\mathrm{K}_{\mathrm{p} \text {,uu. }}$. One of the approaches is to compare the observed liver-to-blood total concentration ratio of positron emission tomography probes (e.g., $\left[{ }^{11} \mathrm{C}\right]$ dehydropravastatin) (Ijuin et al., 2012) in humans with that predicted from experimentally estimated hepatic $\mathrm{K}_{\mathrm{p} \text {,uu }}$ and their unbound fractions in blood and hepatocytes. Another approach is to confirm whether the discrepancy of in vitro $K_{i}$ values with regard to the medium concentration of inhibitors obtained with hepatocytes and recombinant enzymes can be well explained by in vitro $K_{p, u u}$ when target proteins are located inside the hepatocytes (e.g., inhibition of 3-hydroxy-3-methyl-glutaryl-coenzyme A reductase by statins, inhibition of metabolic enzymes and efflux transporters by inhibitor drugs). Such validations should strengthen our theoretical considerations for in vitro $\mathrm{K}_{\mathrm{p} \text {,uu }}$ estimation.

\section{Authorship Contributions}

Participated in research design: Yoshikado, Toshimoto, Nakada, Maeda, Sugiyama.

Conducted experiments: Yoshikado, Nakada, Ikejiri.

Performed data analysis: Yoshikado, Toshimoto, Nakada.

Wrote or contributed to the writing of the manuscript: Yoshikado, Toshimoto, Nakada, Kusuhara, Maeda, Sugiyama.

\section{References}

Baur H, Kasperek S, and Pfaff E (1975) Criteria of viability of isolated liver cells. Hoppe Seylers Z Physiol Chem 356:827-838.

Bi YA, Qiu X, Rotter CJ, Kimoto E, Piotrowski M, Varma MV, Ei-Kattan AF, and Lai Y (2013) Quantitative assessment of the contribution of sodium-dependent taurocholate co-transporting polypeptide (NTCP) to the hepatic uptake of rosuvastatin, pitavastatin and fluvastatin. Biopharm Drug Dispos 34:452-461.

Bradford NM, Hayes MR, and McGivan JD (1985) The use of 36Cl- to measure cell plasma membrane potential in isolated hepatocytes-effects of cyclic AMP and bicarbonate ions. Biochim Biophys Acta 845:10-16.

Brown HS, Wilby AJ, Alder J, and Houston JB (2010) Comparative use of isolated hepatocytes and hepatic microsomes for cytochrome P450 inhibition studies: transporter-enzyme interplay. Drug Metab Dispos 38:2139-2146.

Chu X, Korzekwa K, Elsby R, Fenner K, Galetin A, Lai Y, Matsson P, Moss A, Nagar S, Rosania GR, et al.; International Transporter Consortium (2013) Intracellular drug concentrations and transporters: measurement, modeling, and implications for the liver. Clin Pharmacol Ther 94: 126-141.

Eaton DL and Klaassen CD (1978) Carrier-mediated transport of ouabain in isolated hepatocytes. J Pharmacol Exp Ther 205:480-488.

Edmondson JW, Miller BA, and Lumeng L (1985) Effect of glucagon on hepatic taurocholate uptake: relationship to membrane potential. Am J Physiol 249:G427-G433.

Fitz JG and Scharschmidt BF (1987) Regulation of transmembrane electrical potential gradient in rat hepatocytes in situ. Am J Physiol 252:G56-G64.

Hallifax D and Houston JB (2006) Uptake and intracellular binding of lipophilic amine drugs by isolated rat hepatocytes and implications for prediction of in vivo metabolic clearance. Drug Metab Dispos 34:1829-1836.

He J, Yu Y, Prasad B, Link J, Miyaoka RS, Chen X, and Unadkat JD (2014) PET imaging of Oatpmediated hepatobiliary transport of $[(11) \mathrm{C}]$ rosuvastatin in the rat. Mol Pharm 11:2745-2754.

Ichikawa M, Tsao SC, Lin TH, Miyauchi S, Sawada Y, Iga T, Hanano M, and Sugiyama Y (1992) 'Albumin-mediated transport phenomenon' observed for ligands with high membrane permeability: effect of the unstirred water layer in the Disse's space of rat liver. J Hepatol 16:38-49. Iga T, Eaton DL, and Klaassen CD (1979) Uptake of unconjugated bilirubin by isolated rat hepatocytes. Am J Physiol 236:C9-C14.

Ijuin R, Takashima T, Watanabe Y, Sugiyama Y, and Suzuki M (2012) Synthesis of [(11)C] dehydropravastatin, a PET probe potentially useful for studying OATP1B1 and MRP2 transporters in the liver. Bioorg Med Chem 20:3703-3709.

Giacomini KM, Huang SM, Tweedie DJ, Benet LZ, Brouwer KL, Chu X, Dahlin A, Evers R, Fischer V, Hillgren KM, et al.; International Transporter Consortium (2010) Membrane transporters in drug development. Nat Rev Drug Discov 9:215-236.

Kanduser M, Sentjurc M, and Miklavcic D (2008) The temperature effect during pulse application on cell membrane fluidity and permeabilization. Bioelectrochemistry 74:52-57.

Kletzien RF, Pariza MW, Becker JE, and Potter VR (1975) A method using 3-O-methyl-D-glucose and phloretin for the determination of intracellular water space of cells in monolayer culture. Anal Biochem 68:537-544.

Kristensen LO and Folke M (1984) Volume-regulatory K+ efflux during concentrative uptake of alanine in isolated rat hepatocytes. Biochem J 221:265-268.

Lundquist P, Englund G, Skogastierna C, Lööf J, Johansson J, Hoogstraate J, Afzelius L, and Andersson TB (2014) Functional ATP-binding cassette drug efflux transporters in isolated human and rat hepatocytes significantly affect assessment of drug disposition. Drug Metab Dispos 42:448-458.

Miyauchi S, Sawada Y, Iga T, Hanano M, and Sugiyama Y (1993) Comparison of the hepatic uptake clearances of fifteen drugs with a wide range of membrane permeabilities in isolated rat hepatocytes and perfused rat livers. Pharm Res 10:434-440. 
Neuhoff S, Ungell AL, Zamora I, and Artursson P (2003) pH-dependent bidirectional transport of weakly basic drugs across Caco-2 monolayers: implications for drug-drug interactions. Pharm Res 20:1141-1148.

Nezasa K, Higaki K, Takeuchi M, Nakano M, and Koike M (2003) Uptake of rosuvastatin by isolated rat hepatocytes: comparison with pravastatin. Xenobiotica 33:379-388.

Nezasa K, Takao A, Kimura K, Takaichi M, Inazawa K, and Koike M (2002) Pharmacokinetics and disposition of rosuvastatin, a new 3-hydroxy-3-methylglutaryl coenzyme A reductase inhibitor, in rat. Xenobiotica 32:715-727.

Niemi M, Pasanen MK, and Neuvonen PJ (2011) Organic anion transporting polypeptide 1B1: a genetically polymorphic transporter of major importance for hepatic drug uptake. Pharmacol Rev 63:157-181.

Reinoso RF, Telfer BA, Brennan BS, and Rowland M (2001) Uptake of teicoplanin by isolated rat hepatocytes: comparison with in vivo hepatic distribution. Drug Metab Dispos 29:453-459.

Saito S, Murakami Y, Miyauchi S, and Kamo N (1992) Measurement of plasma membrane potential in isolated rat hepatocytes using the lipophilic cation, tetraphenylphosphonium: correction of probe intracellular binding and mitochondrial accumulation. Biochim Biophys Acta 1111: $221-230$.

Schirris TJ, Ritschel T, Bilos A, Smeitink JA, and Russel FG (2015) Statin lactonization by uridine 5'-diphospho-glucuronosyltransferases (UGTs). Mol Pharm 12:4048-4055.

Shitara Y, Maeda K, Ikejiri K, Yoshida K, Horie T, and Sugiyama Y (2013) Clinical significance of organic anion transporting polypeptides (OATPs) in drug disposition: their roles in hepatic clearance and intestinal absorption. Biopharm Drug Dispos 34:45-78.

Shitara Y and Sugiyama Y (2006) Pharmacokinetic and pharmacodynamic alterations of 3-hydroxy-3-methylglutaryl coenzyme A (HMG-CoA) reductase inhibitors: drug-drug interactions and interindividual differences in transporter and metabolic enzyme functions. Pharmacol Ther 112:71-105.

Shugarts S and Benet LZ (2009) The role of transporters in the pharmacokinetics of orally administered drugs. Pharm Res 26:2039-2054.
Smith DA, Di L, and Kerns EH (2010) The effect of plasma protein binding on in vivo efficacy: misconceptions in drug discovery. Nat Rev Drug Discov 9:929-939.

Smith NF, Figg WD, and Sparreboom A (2005) Role of the liver-specific transporters OATP1B1 and OATP1B3 in governing drug elimination. Expert Opin Drug Metab Toxicol 1:429-445.

Sugano K, Kansy M, Artursson P, Avdeef A, Bendels S, Di L, Ecker GF, Faller B, Fischer H, Gerebtzoff G, et al. (2010) Coexistence of passive and carrier-mediated processes in drug transport. Nat Rev Drug Discov 9:597-614.

Weinman SA, Graf J, and Boyer JL (1989) Voltage-driven, taurocholate-dependent secretion in isolated hepatocyte couplets. Am J Physiol 256:G826-G832.

Wondergem R and Castillo LB (1988) Quinine decreases hepatocyte transmembrane potential and inhibits amino acid transport. Am J Physiol 254:G795-G801.

Yabe Y, Galetin A, and Houston JB (2011) Kinetic characterization of rat hepatic uptake of 16 actively transported drugs. Drug Metab Dispos 39:1808-1814.

Yamazaki M, Suzuki H, Hanano M, Tokui T, Komai T, and Sugiyama Y (1993) Na(+)-independent multispecific anion transporter mediates active transport of pravastatin into rat liver. Am J Physiol 264:G36-G44.

Yamazaki M, Suzuki H, Sugiyama Y, Iga T, and Hanano M (1992) Uptake of organic anions by isolated rat hepatocytes: a classification in terms of ATP-dependency. J Hepatol 14:41-47.

Yoshikado T, Yoshida K, Kotani N, Nakada T, Asaumi R, Toshimoto K, Maeda K, Kusuhara H, and Sugiyama Y (2016) Quantitative analyses of hepatic OATP-mediated interactions between statins and inhibitors using PBPK modeling with a parameter optimization method. Clin Pharmacol Ther 100:513-523.

Address correspondence to: Dr. Yuichi Sugiyama, Sugiyama Laboratory, RIKEN Innovation Center, RIKEN, 1-7-22 Suehiro-cho, Tsurumi-ku, Yokohama, Kanagawa 230-0045, Japan. E-mail: ychi.sugiyama@riken.jp 